\title{
Long-term follow up of feline leukemia virus infection and characterization of viral RNA loads using molecular methods in tissues of cats with different infection outcomes
}

Helfer-Hungerbuehler, A Katrin ; Widmer, Stefan ; Kessler, Yvonne ; Riond, Barbara ; Boretti, Felicitas S ; Grest, Paula ; Lutz, Hans ; Hofmann-Lehmann, Regina

\begin{abstract}
It is a remarkable feature for a retrovirus that an infection with feline leukemia virus (FeLV) can result in various outcomes. Whereas some cats contain the infection and show a regressive course, others stay viremic and succumb to the infection within a few years. We hypothesized, that differences in the infection outcome might be causally linked to the viral RNA and provirus loads within the host and these loads therefore may give additional insight into the pathogenesis of the virus. Thus, the goals of the present study were to followup on experimentally infected cats and investigate tissues from cats with different infection outcomes using sensitive, specific TaqMan real-time PCR and reverse transcriptase (RT)-PCR. Nineteen experimentally FeLVA/Glasgow-1-infected cats were categorized into having regressive, progressive or reactivated FeLV infection according to follow-up of FeLV p27 antigen detection in the blood. Remarkably, regressively infected cats showed detectable provirus and viral RNA loads in almost all of the 27 tested tissues, even many years after virus exposure. Moreover, some regressively infected cats reactivated the infection, and these cats had intermediate to high viral RNA and provirus tissue loads. The highest loads were found in viremic cats, independent of their health status. Tissues that represented sites of virus replication and shedding revealed the highest viral RNA and provirus loads, while the lowest loads were present in muscle and nerve tissues. A supplementary analysis of 20 experimentally infected cats with progressive infection revealed a median survival time of 3.1 years (range from 0.6 to 6.5 years); $\sim 70 \%$ ( $\mathrm{n}=14$ ) of these cats developed lymphoma, while leukemia and non-regenerative anemia were observed less frequently. Our results demonstrate that the different infection outcomes are associated with differences in viral RNA and provirus tissue loads. Remarkably, no complete clearance of FeLV viral RNA or provirus was detected in cats with regressive infection, even up to 12 years after exposure. In several cases FeLV reactivation could be observed. Thus, retroviruses integrated as provirus into the host's genome, could not be eliminated completely by the host and maintained their full potential for replication and reactivation.
\end{abstract}

DOI: https://doi.org/10.1016/j.virusres.2014.12.025

Posted at the Zurich Open Repository and Archive, University of Zurich

ZORA URL: https://doi.org/10.5167/uzh-105626

Journal Article

Accepted Version

Originally published at:

Helfer-Hungerbuehler, A Katrin; Widmer, Stefan; Kessler, Yvonne; Riond, Barbara; Boretti, Felicitas S; Grest, Paula; Lutz, Hans; Hofmann-Lehmann, Regina (2015). Long-term follow up of feline leukemia virus infection and characterization of viral RNA loads using molecular methods in tissues of cats with different infection outcomes. Virus Research, 197:137-150. 
DOI: https://doi.org/10.1016/j.virusres.2014.12.025 


\section{Long-term follow up of feline leukemia virus infection}

2 and characterization of viral RNA loads using

3 molecular methods in tissues of cats with different

4 infection outcomes

5

6 A. Katrin Helfer-Hungerbuehler ${ }^{1 \S}$, Stefan Widmer ${ }^{1}$, Yvonne Kessler ${ }^{1}$, Barbara

$7 \quad$ Riond $^{1}$, Felicitas S. Boretti ${ }^{2}$, Paula Grest ${ }^{3}$, Hans Lutz ${ }^{1}$ and Regina Hofmann-

8 Lehmann $^{1}$

9

$10{ }^{1}$ Clinical Laboratory and Center for Clinical Studies, Vetsuisse Faculty, University of

11 Zurich, Zurich, Switzerland

$12{ }^{2}$ Clinic for Small Animal Internal Medicine, Vetsuisse Faculty, University of Zurich,

13 Zurich, Switzerland

$14{ }^{3}$ Institute of Veterinary Pathology, Vetsuisse Faculty, University of Zurich, Zurich,

15 Switzerland

16

$17{ }^{\S}$ Corresponding author

18

19 Mailing address: Clinical Laboratory, Vetsuisse Faculty, University of Zurich,

20 Winterthurerstr. 260, 8057 Zurich, Switzerland.

21 Phone: +414463583 11. Fax: +41446358923.

22 E-mail: khungerbuehler@ vetclinics.uzh.ch 
1 Email addresses:

2

AKH: khungerbuehler@vetclinics.uzh.ch

3

SW: swidmer@access.uzh.ch

4

YK:y.kessler@bluewin.ch

5

BR: briond@vetclinics.uzh.ch

6

FSB: fboretti@vetclinics.uzh.ch

7

PG: grest@ vetpath.uzh.ch

8

HL: hanslutz@me.com

9

RHL: rhofmann@vetclinics.uzh.ch

10 


\section{Abstract}

2 It is a remarkable feature for a retrovirus that an infection with feline leukemia virus

3 (FeLV) can result in various outcomes. Whereas some cats contain the infection and

4 show a regressive course, others stay viremic and succumb to the infection within a

5 few years. We hypothesized, that differences in the infection outcome might be

6 causally linked to the viral RNA and provirus loads within the host and these loads

7 therefore may give additional insight into the pathogenesis of the virus. Thus, the

8 goals of the present study were to follow-up on experimentally infected cats and

9 investigate tissues from cats with different infection outcomes using sensitive,

10 specific TaqMan real-time PCR and reverse transcriptase (RT)-PCR.

11 Nineteen experimentally FeLV-A/Glasgow-1-infected cats were categorized into

12 having regressive, progressive or reactivated FeLV infection according to follow-up

13 of FeLV p27 antigen detection in the blood. Remarkably, regressively infected cats

14 showed detectable provirus and viral RNA loads in almost all of the 27 tested tissues,

15 even many years after virus exposure. Moreover, some regressively infected cats

16 reactivated the infection, and these cats had intermediate to high viral RNA and

17 provirus tissue loads. The highest loads were found in viremic cats, independent of

18 their health status. Tissues that represented sites of virus replication and shedding

19 revealed the highest viral RNA and provirus loads, while the lowest loads were

20 present in muscle and nerve tissues.

21 A supplementary analysis of 20 experimentally infected cats with progressive

22 infection revealed a median survival time of 3.1 years (range from 0.6 to 6.5 years);

$23 \sim 70 \%(\mathrm{n}=14)$ of these cats developed lymphoma, while leukemia and non-

24 regenerative anemia were observed less frequently. 
1 Our results demonstrate that the different infection outcomes are associated with

2 differences in viral RNA and provirus tissue loads. Remarkably, no complete

3 clearance of FeLV viral RNA or provirus was detected in cats with regressive

4 infection, even up to 12 years after exposure. In several cases FeLV reactivation could

5 be observed. Thus, retroviruses integrated as provirus into the host's genome, could

6 not be eliminated completely by the host and maintained their full potential for

7 replication and reactivation.

9 Keywords

10 FeLV; retrovirus; tissue loads; reactivation; latent infection; qPCR

\section{Abbreviations}

13 Bm, bone marrow; cDNA, complementary DNA; FeLV, Feline Leukemia Virus; FIV,

14 Feline Immunodeficiency Virus; GAPDH, glyceraldehyde-3-phosphate

15 dehydrogenase; gDNA, genomic DNA; ln., lymph node; RT-PCR, reverse

16 transcriptase-PCR; RPS7, ribosomal protein S7; qPCR, quantitative TaqMan real-

17 time PCR;

\section{$19 \quad \mathbf{1 . 1}$ Introduction}

20 Retroviral infections and their impact on human and animal health are of major

21 scientific and public interest. It is fundamental to understand the underlying biology

22 of retroviral infections to develop successful antiviral strategies, such as preventive

23 and therapeutic measures. Animal models are needed to investigate host-virus

24 interactions. One established animal model for tumor and retroviral research that has

25 been used for nearly 50 years is feline leukemia virus (FeLV) infection in cats. 
1 FeLV is a gammaretrovirus of domestic cats and closely related wild felids [1]. An

2 infection with the virus may cause severe diseases, including cytoproliferative

3 disorders, which are characterized by tumor growth and leukemia, or cytosuppressive

4 diseases with immunodeficiency and myelosuppression. Vaccines against FeLV

5 infection have been commercially available for almost three decades [1-3] and are

6 highly effective [4-6].

7 The discovery of FeLV in 1964 [7] was succeeded by many studies elucidating the

8 pathogenesis and course of FeLV infection [8-10]. After FeLV exposure, the tonsils

9 and local lymph nodes in the oropharynx are infected. During early cell-associated

10 viremia, the virus spreads into the circulating lymphocytes and monocytes, thereby

11 distributing the virus to lymphoid tissues throughout the body. A significant step

12 during FeLV infection is infection of the bone marrow (bm), where neutrophil and

13 platelet precursor cells become virus-positive. With the establishment of persistent

14 viremia, $\mathrm{CD}^{+}, \mathrm{CD}^{+}$and $\mathrm{B}$ lymphocytes, granulocytes and monocytes are infected in

15 the blood, thereby spreading the virus throughout the body, where it infects many

16 organs and tissues $[11,12]$.

17 A new cycle of infection starts with the shedding of the virus. Horizontal transmission

18 mainly occurs directly from cat to cat. In most cases, transmission occurs through

19 contact with saliva (licking, mutual grooming and sharing of dishes); however, FeLV

20 may also be transmitted via blood, feces and milk [1, 13-16].

21 Until recently, the outcome of FeLV-infected cats was categorized using mainly the 22 results from virus isolation, immunofluorescence and enzyme-linked immunosorbent 23 assays (ELISAs). The introduction of new molecular methods, such as the 24 development of sensitive, specific TaqMan real-time PCR and reverse transcriptase 25 (RT)-PCR, helped to shed new light on the biology and pathogenesis of retroviral 
1 infections [4, 17-20]. Using quantitative TaqMan real-time PCR (qPCR) and RT-

2 qPCR, the detection and quantification of provirus and viral RNA was achieved. It

3 has been demonstrated that the detection of provirus by real-time PCR is a more

4 sensitive diagnostic marker for identifying FeLV-exposed cats compared to

5 previously used methods [18]. Thus, the FeLV exposure rates were highly

6 underestimated for years. In Switzerland, 6\% of the Swiss pet cat population was

7 FeLV p27-positive. However, an additional 10\% was provirus-positive with the

8 absence of detectable antigenemia [18]. These cats must have been exposed to FeLV

9 but likely recovered from viremia.

10 It is a remarkable feature of FeLV that an infection with the virus can result in several

11 different outcomes [9, 10, 13, 21-24]. According to the information of provirus and

12 plasma viral RNA loads, the host-response categories were refined and described as

13 follows. The absence of FeLV provirus, virus and antigen after challenge was

14 categorized as abortive infection [20, 25-27]. Cats classified as having experienced an

15 abortive infection may not be distinguished from those never exposed to FeLV on the

16 basis of p27 ELISA and real-time PCR of blood and tissues [20]. In some cats that

17 had undergone low-dose exposure, seroconversion was detected as a sign of FeLV

18 infection by means of the feline oncornavirus-associated cell membrane antigen assay

19 [27]. Cats with regressive infection show either transient or undetectable antigenemia.

20 They develop an efficient immune response with neutralizing antibodies [28, 29] and

21 FeLV-specific cytotoxic T lymphocytes [18, 30, 31]. It was demonstrated that cats

22 undergoing regressive infection display provirus and plasma viral RNA loads similar

23 to those in cats with progressive infection during the first week after infection.

24 However, they manage to reduce plasma viral RNA and provirus loads to moderate or

25 low levels, while the loads in cats with a progressive infection remain high $[18,26]$. 
1 Viral RNA loads in cats with regressive infection may or may not be cleared below

2 detectable levels in the blood [32]. Approximately one-third of all infected cats

3 become persistently viremic [33]. These cats were shown to have constantly high

4 provirus and plasma viral RNA loads. The cats lack effective FeLV-specific humoral

5 and cellular immunity [1,34], and they ultimately succumb to FeLV-associated

6 diseases within some years of infection [35].

7 Reactivation of FeLV infection in aviremic cats (p27-negative, but provirus positive)

8 with and without immune suppression has been reported in several studies $[15,26$,

9 36-39]. The study by Pedersen et al. (1984) compared the reactivation of latent FeLV

10 infection after methylprednisolone administration: FeLV Rickard was the easiest to

11 activate compared to an isolate from a leopard cat (CT600-FeLV) and the Snyder-

12 Theilen strain (ST-FeLV) [37]. Thus, the potential for reactivation seemed to be

13 associated with the FeLV isolate [37]. In the absence of experimental immune

14 suppression, only a limited number of cases of reactivation of FeLV infection have

15 been reported $[15,20,26,36,37]$. In some of these cats, natural stress was thought to

16 be the initiator of reactivation [37]; in another cat, the breakdown of the immune 17 system as a result of end-stage feline immunodeficiency virus (FIV) initiated FeLV 18 reactivation [36].

19 We hypothesized that differences in the infection outcome of FeLV-infected cats 20 might be causally linked to differences in viral RNA and provirus loads, not only in 21 the blood but also in tissues. Most FeLV pathogenesis studies were conducted prior to 22 the development of sensitive, specific qPCR and RT-qPCR for the detection and 23 quantification of FeLV provirus and viral RNA loads [32]. Thus, it was the aim of this 24 study to follow-up on experimentally infected cats and to employ sensitive molecular 25 methods to investigate tissues from cats with different infection outcomes to gain 
1 better insight into FeLV pathogenesis, its target tissues and the influence of the viral

2 distribution on the outcome of the infection. In particular, 27 tissues from 19

3 experimentally FeLV-infected cats with different duration and outcome of infection

4 were investigated for the presence and quantity of FeLV provirus and viral RNA.

\section{$6 \quad 2.1$ Methods}

\section{$7 \quad$ 2.1.1 Sample description}

8 All specific pathogen-free (SPF) cats included in this study were in experimental

9 studies officially approved by the veterinary office of the Swiss Canton of Zurich (197/89, 43/90, 66/91, 131/91, 329/91, 56/95, 30/2003, 59/2005, 99/2007, 11/2011

11 and 160/2010). The cats were kept in groups under optimal ethological conditions as 12 previously described [40]. The cats had been experimentally infected with FeLV13 A/Glasgow-1 in the above-mentioned studies $[4,5,26,36,40-43]$ and were 14 euthanized for reasons unrelated to the present study.

15 The 19 cats in the tissue-load study showed different FeLV infection outcomes and 16 were grouped into four response categories. The first response category, consisting of 17 four persistently viremic cats (\#15, \#23, \#64, \#R1, ages 0.6 to 1.3 years) that were 18 infected for less than 1 year and did not have symptoms at the time of euthanasia, was 19 termed "viremic healthy" [4, 41]. The second category included another five persistently viremic cats (\#19,\#32, \#67, \#B1 and \#B3, ages 2.6 to 4.5 years) that were

21 infected for more than 2 years and developed disease due to FeLV-related lymphoma 22 were named "viremic ill" [4, 42]. The third category "regressive" contained five 23 clinically healthy cats (\#68, \#258, \#260, \#271 and \#B9, ages 2.9 to 13.8 years) with a 24 regressive infection and transient or undetectable antigenemia [4, 5, 42]. Response category four "reactivated" included five cats (\#30, \#70, \#HBU1, \#GCN4 and \#261, 
1 ages 0.7 to 9.6 years) that showed either undetectable or transient viremia after

2 experimental infection but then reactivated [4, 5, 26, 36, 40, 43](Table 2). Cat \#30

3 was co-housed with cats that had become persistently infected [26]. The other four

4 cats, had not been exposed to persistently infected cats for several weeks to years: Cat

5 \#HBU1 was housed with regressively infected cats only [43], cat \#GCN4 was

6 separated from persistently infected cats 45 weeks before reactivation [40], in cat

$7 \quad \# 261$ and cat \#70, the last potential exposure to FeLV was 18 month and 46 weeks

8 prior to FeLV reactivation, respectively [26, 36]. The following 27 tissues were

9 collected upon necropsy: thyroid, bm, mesenteric lymph node (ln.), popliteal ln.,

10 sternal ln., submandibular ln., spleen, tonsil, thymus, parotid gland, mandibular gland,

11 duodenum, ileum, jejunum, colon, rectum, brain, sciatic nerve, spinal cord, kidney,

12 urinary bladder, aorta, diaphragm, femoral muscle, myocardium, lung and liver. In

13 addition, tumor tissue was investigated if present and categorized as described [44].

14 All tissues were collected immediately after euthanasia, snap frozen in liquid nitrogen

15 following collection and stored at $-80^{\circ} \mathrm{C}$ until nucleic acids were extracted.

16 In addition, information on 20 persistently FeLV-A/Glasgow-1-infected cats was used 17 to assess the duration and clinical outcome of an average persistent FeLV infection in

18 SPF cats. This group of cats included the 5 persistently infected cats (group 2 termed 19 "viremic ill") in the tissue load study (Table 2) as well as 15 additional cats fitting this 20 category (Table 1).

\section{$21 \quad$ 2.1.2 Serological assays and virus isolation}

22 FeLV viremia was determined by p27 sandwich ELISA as described [45]. Values

23 above $4 \%$ of the positive control (culture supernatant of FL-74 feline lymphoblastoid 24 cell line permanently infected with FeLV) were considered positive [4]. According to 25 the European Pharmacopoeia (2005), a cat was considered persistently infected when 
1 it was FeLV p27-positive for three consecutive weeks or on five occasions between

2 weeks 3 and 15 post-exposure.

3 The presence of infectious FeLV was determined in vitro by inoculation of

4 heparinized plasma samples onto QN10S cells [46].

5 To detect FeLV latency, bm was cultured in the presence of hydrocortisone [5].

\section{$6 \quad$ 2.1.3 Nucleic acid extractions and cDNA production}

7 Genomic DNA (gDNA) and RNA were extracted from tissues as previously described

$8 \quad[47,48]$. For all RNA and DNA extractions, negative controls consisting of $100 \mu 1$ of

9 phosphate buffered saline were prepared for each batch to monitor cross-

10 contamination. According to earlier results levels of gDNA contamination in RNA

11 extractions were $<1 \%$ [47].

12 The quality of the RNA extraction was tested by real-time RT-PCR, with the Reverse

13 Transcriptase qPCR Mastermix (Eurogentec, Seraing, Belgium). For this purpose, 5

$14 \mu \mathrm{l}$ of extracted RNA or RNA standard was amplified in a total reaction volume of 25

$15 \mu \mathrm{l}$ with glyceraldehyde-3-phosphate dehydrogenase (GAPDH) primers and probe

16 [49]. For samples with GAPDH concentrations higher than 10,000 copies per reaction

17 and a negative extraction control, the RNA was reverse transcribed into

18 complementary DNA (cDNA) using the High Capacity cDNA Reverse Transcription

19 Kit (Applied Biosystems, Rotkreuz, Switzerland) and random primers according to

20 the manufacturer's instructions.

$21 \quad$ 2.1.4 TaqMan fluorogenic real-time PCR assay

22 gDNA and cDNA were amplified and quantified on a Rotor-Gene 6000 real-time

23 rotary analyzer (Corbett, Mortlake, Australia) or an ABI Prism 7700 sequence

24 detection system (Applied Biosystems). 
1 FeLV viral loads from all three subtypes of FeLV, -A, -B, and -C, but not endogenous

2 FeLV, were amplified from cDNA or gDNA using TaqMan real-time PCR (U3

3 region) as previously described [19]. FeLV viral RNA loads were normalized to two

4 reference genes: GAPDH [49], the most commonly used reference gene, and

5 ribosomal protein S7 (RPS7), the best reference gene for various feline tissues [47].

6 Because two LTR U3 target sequences are present for each provirus copy, the number

7 of provirus copies was calculated by dividing the number of copies of $\mathrm{U} 3$, as

8 determined by real-time PCR, by two. This number of provirus copies was then

9 divided by the number of feline albumin (fALB) copies measured by real-time PCR,

10 as described previously [48], to determine the provirus copy numbers per cell.

\section{$11 \quad 2.1 .5$ Statistics}

12 For statistical analysis, the tissues were integrated into physiological tissue groups

13 (Table 3). Statistical analyses were performed using GraphPad Prism for Windows, 14 Version 5.03 (GraphPad software, San Diego, CA). Differences among three and 15 more groups were analyzed by the non-parametric Kruskal-Wallis one way ANOVA 16 by Ranks ( $p_{\mathrm{KW}}$ ) for unpaired samples or the non-parametric Friedman test for paired 17 samples $\left(p_{\mathrm{F}}\right)$ followed by the Dunn's Multiple Comparison test $\left(p_{\mathrm{D}}\right)$. Differences 18 between two groups were tested for significance using the non-parametric Mann19 Whitney U-test for unpaired samples $\left(p_{\mathrm{MWU}}\right)$ or the Wilcoxon signed rank test for 20 paired samples $\left(p_{\mathrm{W}}\right)$. Loads (viral RNA and provirus) were analyzed using the 21 Spearman rank test for correlation. Moreover, the association between the "major 22 diagnosis at necropsy" and the age of the cat at infection (categorized in "young" $[<1$ 23 year] and "older" [ $\geq 1$ year]) was tested by Chi-square test ( $\left.p_{\text {Chi }}\right)$. A $p$-value less than 240.05 was considered significant. 


\section{$1 \quad 3.1$ Results}

2 3.1.1 Long-term observation: duration and clinical outcome of experimentally 3 persistent FeLV-A/Glasgow-1 infection

4 Currently, only limited data are available on the survival times and terminal outcome

5 of infection of experimentally FeLV-infected cats [26, 50, 51]. In our SPF facility,

6 some cats persistently infected with FeLV showed remarkably long survival times,

7 while others succumbed to infection quickly. To substantiate and assess this

8 observation, we summarized data available on 20 cats that had been experimentally

9 exposed to FeLV-A/Glasgow-1 and had developed persistent infection. Persistently

10 viremic cats lived an average (median) of 3.1 years with FeLV infection $(0.6-6.5$

11 years, $n=20$ ) before they had to be euthanized for humane reasons (Table 1). The

12 major diagnosis at necropsy included lymphoma (70\%), leukemia (15\%) and non-

13 regenerative anemia (15\%). Significant differences in the survival time could be

14 shown between cats with different outcome ( $\left.p_{\mathrm{KW}}: 0.0212\right)$ : cats that developed a

15 lymphoma survived an average of 3.6 years with the infection (from 1.6 to 6.5 years;

$16 \mathrm{n}=14$ ), whereas cats that showed non-regenerative anemia lived an average of only

170.6 years (from 0.6 to 1.1 years; $\mathrm{n}=3 ; p_{\mathrm{MWU}}=0.0098$ ). The three cats that suffered

18 from leukemia survived longest (median: 5.3 years, from 1.8 to 5.3 years; $n=3$ ). We

19 investigated whether the age at infection had an effect on the survival time. The cats

20 included in this study had been infected between the ages of 10 and 59 weeks (Table

21 1). No correlation was found between the age at infection and the survival time of the

22 cats (data not shown). Moreover, cats with different major diagnosis at necropsy

23 (lymphoma, leukemia, anemia) did not differ significantly in the age at infection ( $p_{\mathrm{KW}}$

$24=0.8077)$ and cats infected at the age $<1$ year did not have different major diagnosis

25 at necropsy compared with cats infected at the age of $\geq 1$ year $\left(p_{\text {Chi }}=0.5471\right)$. 


\section{$1 \quad$ 3.1.2 Tissue load study: categorization of cats}

2 In the tissue load study, 19 FeLV-infected cats with various infection outcomes were

3 included (Table 2). Terminally collected plasma samples were examined for the

4 presence of FeLV p27 capsid antigen by ELISA. The cats were grouped into four

5 categories: regressive, reactivated, viremic ill and viremic healthy. Significant

6 differences were found among the four categories (Fig. $1 \mathrm{~A} ; p_{\mathrm{KW}}=0.0019$ ). Highest

7 terminal p27 levels were detected in plasma samples from viremic ill cats that had

8 developed lymphoma, whereas negative levels were found - per definition - in cats

9 with regressive infection (Fig. 1A; Supplementary Fig. 1). Viremic ill cats had

10 significantly higher p27 antigen blood loads than viremic healthy cats $\left(p_{\mathrm{MWU}}=\right.$

11 0.0159; Supplementary Fig. 1). Cats, that reactivated the infection and developed

12 FeLV-associated disease had intermediate p27 loads (between the categories

13 regressive and viremic ill), similar to viremic healthy cats (Fig. 1).

\subsubsection{Follow-up of cats with reactivation of FeLV infection}

15 Cats with reactivated FeLV infection were of particular interest, but only a few 16 studies that have observed the cats throughout infection and reactivation are available.

17 In the tissue load study, we included five cats with reactivated FeLV infection. For 18 two cats (cats \#30 and \#GCN4), p27 antigen ELISA, virus isolation from blood and 19 virus isolation from bm in the presence of hydrocortisol (test for latency) were 20 negative at the tested time points $[26,40]$ until the infection was reactivated in both 21 cats. Cat \#30 became FeLV antigen-positive in week 44 post infection (p.i.), with 22 increasing antigen levels thereafter (Fig. 1B) and showed a lymphoma in the thymus 23 at the time of euthanasia, 10 weeks later [26] (Table 2). Cat \#GCN4 developed a $24 \mathrm{CD}^{+}$T-cell lymphoma of the thymus, mediastinum and the sternal $\ln$ and was found 25 to be p27-positive at the time of euthanasia, 1.2 years p.i. (Fig. $1 \mathrm{~B}$ and Table 2 [40]). 
1 The three remaining cats in this category (\#HBU1, \#261 and \#70) were all transiently

2 p27-positive one to several time points after FeLV infection (between week 2 and 7),

3 but subsequently cleared the antigenemia (Fig. 1B). The infection was reactivated

4 between 0.5 and 8.5 years after the initial infection. In cat \#HBU1, FeLV latency was

5 detected by bm culture 17 weeks p.i.. At week 26, the animal was highly positive for

6 FeLV p27 (113\%; [Fig. 1B]) and had developed a lymphoma in the thymus,

7 mesenteric ln., liver, kidney and bm with secondary leukemia (white blood cell count

$849 \times 10^{3}$ cells $/ \mu 1$ with $75 \%$ lymphoblasts [Table 2]).

9 Cat \#261 was described in detail elsewhere [36]. Briefly, in addition to the FeLV10 A/Glasgow-1 infection, the cat was co-infected with FIV. After the cat had become 11 p27-negative, no latency could be detected by bm culture. At the age of 9.6 years, the 12 cat had developed severe non-regenerative anemia, leukopenia and a multicentric 13 lymphoma (Table 2). Simultaneous with disease development, the cat again became 14 FeLV p27 antigen-positive [36] (Fig. 1B).

15 Finally, in cat \#70, latent infection was detectable by bm culture collected at week 17 16 p.i. but not anymore at week 43 p.i.. Concurrent with the reactivation of FeLV 17 infection during week 101, a lymphoma in the thymus, tonsil, spleen, kidney and 18 various ln. was detectable [26] (Fig. 1B and Table 2).

\subsubsection{FeLV viral RNA loads in tissues of cats with different infection outcome}

20 The exogenous FeLV tissue loads, measured by RT-qPCR, were compared among the

21 categories with different infection outcome. Overall, significantly lower viral RNA 22 loads were found in cats with a regressive course of infection compared to viremic 23 cats, healthy or ill, and cats with reactivation of infection (Fig. $1 \mathrm{C} ; p_{\mathrm{KW}}<0.0001$ ). In 24 detail, the quantification of viral RNA in 27 tissues from cats with different infection 25 outcome showed detectable loads in nearly all investigated tissues, (Fig. 2, 
1 normalization depicted with RPS7, normalization with GAPDH not shown). The cat

2 category, classified as having a regressive infection, showed the lowest loads of FeLV

3 viral RNA (Fig. 2A). Nonetheless, FeLV viral RNA was detectable in most tissues

4 from at least some of the cats in this category, with the exception of five tissues (the

5 sciatic nerve, spinal cord, urinary bladder, diaphragm, and aorta; Fig. 2A). Viral RNA

6 could be found in all tissues from all cats in the other infection outcome categories

7 (Fig. 2B-D), with the exception of only three samples (Fig. 2B). A comparison

8 between all tissues within each category revealed only statistically significant lower

9 FeLV loads in the femoral muscle of viremic cats, when compared with the 10 mandibular gland and the duodenum (Fig. 2D; $\left.p_{\mathrm{D}}<0.05\right)$.

11 When comparing different tissues, the highest FeLV viral RNA loads were found in 12 the intestinal tract, lymphoid tissues and salivary glands, whereas the lowest loads 13 were detected in the nervous system. This finding was confirmed and found to be 14 statistically significant when comparing the FeLV viral RNA loads in single tissues of 15 all FeLV viremic cats (viremic healthy and viremic ill combined; $p_{\mathrm{F}}<0.0001$ ). 16 Significantly higher FeLV loads were found in the duodenum than in the spinal cord, 17 kidney, femoral muscle $\left(p_{\mathrm{D}}<0.01\right)$, brain, sciatic nerve and myocardium $\left(p_{\mathrm{D}}<0.05\right)$. 18 In addition, the FeLV viral RNA load in the mandibular gland was significantly 19 higher than in the femoral muscle $\left(p_{\mathrm{D}}<0.01\right)$ and spinal cord $\left(p_{\mathrm{D}}<0.05\right)$. 20 Furthermore, a significant difference was detected between the FeLV viral RNA loads 21 in tonsils and the femoral muscle ( $p_{\mathrm{D}}<0.05$, data not shown).

22 The investigated tissues were also categorized into functional tissue groups (Table 3 ).

23 The FeLV viral RNA loads were compared between functional tissue groups in the 24 four response categories; a tendency was observed, with the lowest loads in cats with 25 regressive outcome $<$ reactivated $<$ viremic healthy $\leq$ viremic ill, and was independent 
1 of the reference gene used for normalization (for representative examples, see Fig. 3A

2 and B). All investigated functional groups showed statistically significant differences

3 between regressive and viremic ill cats; viremic ill cats had approximately 1000-times

4 higher loads compared to regressive cats (for representative examples, see Fig. 3A

5 and B). Whereas, viral RNA loads were clearly lowest in samples obtained from cats

6 with a regressive infection, the loads from the reactivated tissue group often revealed

7 similar levels to the samples obtained from cats undergoing a viremic infection (for a

8 representative example, see Fig. 3B).

9 The FeLV viral RNA load was also compared between the response categories in

10 single tissues, confirming the tendency observed in functional tissue groups, with the

11 lowest loads in regressive and highest loads in viremic ill cats (for representative 12 examples, see Fig. 3C and D). The variability in viral RNA loads in a single tissue 13 was highest between different cats of the regressive category (data not shown).

\subsubsection{FeLV provirus loads in tissues of cats with different outcome}

15 Analogous to the quantification of FeLV viral RNA loads in cats with different FeLV

16 infection outcomes, the provirus loads were also quantified. To determine the cell number of the input gDNA, FeLV provirus copy numbers were normalized to fALB [48]. In contrast to the results of the FeLV viral RNA loads, FeLV provirus was

19 detectable in some samples from each investigated organ, although no provirus was 20 found in a few single samples (22 of 459 measurements), which was indicative of 21 provirus numbers around the detection limit. Similar to the results of the FeLV viral 22 RNA loads, provirus loads were highest in the intestinal tract and lymphoid tissues, 23 whereas the lowest FeLV provirus loads were detected in the nervous system (Fig. 4). 24 In addition, overall, the provirus loads were lowest in cats with regressive FeLV 25 infection, followed by cats with reactivated infection (intermediate loads) and viremic 
1 cats (highest loads, Fig. 1D). In the category of the viremic healthy cats, statistically

2 higher FeLV provirus loads were detected in the bm compared with the brain and

3 urinary bladder $\left(p_{\mathrm{D}}<0.05 ;\right.$ Fig. $\left.4 \mathrm{C}\right)$. In the viremic ill response category, a

4 significantly lower FeLV provirus load was found in the brain compared to sternal ln.

$5 \quad\left(p_{\mathrm{D}}<0.01\right)$, bm, mesenteric ln., spleen, mandibular gland and jejunum $\left(p_{\mathrm{D}}<0.05\right.$;

$6 \quad$ Fig. 4D).

7 Comparisons between the four response categories in specific functional tissue groups

8 confirmed the tendency of lowest provirus loads in cats with regressive outcome <

9 reactivated $<$ viremic healthy $\leq$ viremic ill (for representative examples, see Fig. 5A

10 and B). Statistically significant differences were found between regressive and

11 viremic ill cats for all investigated functional groups. Differences between the

12 medians of viremic ill and regressive tissue groups always exceeded four orders of

13 magnitude.

14 FeLV provirus loads in single tissues of the four response categories were compared,

15 confirming the lowest levels in samples from the category of regressive cats (for

16 representative examples, see Fig. 5C and D). The provirus loads in samples from the

17 reactivated category were mainly found to be between those of the regressive and

18 viremic categories, with some reaching levels as high as those detected in the viremic 19 category.

$21 \quad$ 3.1.6 Correlation between viral RNA and provirus loads

22 Spearman correlation coefficients were determined to assess the linear relationship 23 between viral RNA and provirus loads. When all tissues from all cats were included, a 24 linear relationship between viral RNA and provirus loads was identified (413 samples 25 analyzed, $\mathrm{r}=0.8500, p<0.0001$; Supplementary Fig. 2A). When single tissues were 
1 analyzed, the strongest linear relationship was found in the mandibular gland $(\mathrm{n}=16$,

$2 \mathrm{r}=0.9617, p<0.0001)$.

3 Ratios between viral RNA and provirus loads were compared between the different

4 response categories. Significantly lower viral RNA/provirus ratios were detected in

5 cats with a regressive course of infection compared with the other response categories

$6 \quad\left(p_{\mathrm{KW}}<0.001 ;\right.$ Supplementary Fig. 2B). In these cats, the virus might not be

7 replicating as actively as in the other categories. In addition, significant differences in

8 the ratios of the viral RNA and provirus loads were also found when viremic ill cats

9 were compared with viremic healthy or reactivated cats $\left(p_{\mathrm{KW}}<0.05\right.$; Supplementary

10 Fig. 2B).

\section{2 \\ 3.1.7 FeLV viral RNA and provirus loads in tumor tissue}

13 FeLV viral RNA and provirus loads in tumors from viremic ill and reactivated cats 14 were compared with the respective healthy tissue. No statistically relevant difference 15 was found for provirus or viral RNA loads between the healthy and tumor tissue 16 groups (data not shown).

\subsection{Discussion}

19 This is the first study to systematically measure the viral RNA and provirus tissue loads in cats with different FeLV infection outcomes. Differences were detected in the

21 viral RNA and provirus tissue loads among the different response categories. While

22 the cats with regressive infection remarkably had detectable viral RNA loads in many

23 tissues, this category of cat was found to have lowest viral RNA and proviral tissue

24 loads, the highest loads were found in the cats that had undergone progressive

25 infection, independent of the health status. The fact that FeLV was detectable in the 
1 form of viral RNA and DNA in most examined tissues of regressive cats has

2 important implications for retrovirus research as well as for clinicians who need to

3 expect reactivation of FeLV in these cats. The biological importance of provirus-

4 positive cats has been neglected for decades - due to unawareness of the subject

5 (inability to detect these cats using older methods). Our results emphasize that

6 regressive cats need to be considered if the aim is to further decrease FeLV infection

7 in the domestic cat population.

8 We also analyzed the life expectancy of persistently infected cats after experimental

9 FeLV infection. Persistently infected cats lived an average of 3.1 years before they

10 were euthanized for humane reasons (development of FeLV-associated fatal diseases).

11 It had been reported that the life expectancy of experimentally FeLV-infected animals

12 greatly depends on the virus strain, route of infection and age and thus may vary

13 significantly [52]. For example, this has been shown for neonatal cats that were

14 inoculated with different FeLV-plasmid DNA; plasmid DNA from the Rickard strain

15 (pFRA) resulted in an average survival of 49 weeks p.i., whereas the survival time for

16 neonates inoculated with pF6A, a molecular clone of subgroup A FeLV which is

17 considered to be highly infectious but weakly pathogenic, was over 67 weeks [52]. In

18 the current study, the average life expectancy of the cats after FeLV-A/Glasgow-1

19 infection was similar to that of naturally FeLV-infected, which was reported to be 2.4

20 years in a large study of Levy et al. [53] and 3 to 4 years by McClelland and collegues

21 [35]. Some cats lived up to 6.5 years with persistent FeLV-infection in the present

22 study. Our results extend previous findings and show that the period until cats develop

23 FeLV-associated disease may be several years [35]. A persistent FeLV infection

24 should never be a death sentence per se for the infected cat. However, it needs to be 
1 considered that persistently infected cats are constant virus shedders and therefore

2 must be kept isolated from non-infected cats to prevent infection.

3 The viral RNA and provirus tissue loads in persistently infected cats of different

4 health status did not differ significantly. However, when we calculated the viral RNA

5 to provirus ratio, viremic healthy cats had significantly lower ratios than viremic ill

6 cats (Supplementary Fig. 2B). The higher ratio in cats that had developed FeLV-

7 associated diseases may be indicative of a higher degree of viral replication, which

8 would be in agreement with the higher levels of FeLV p27 antigen that were found in

9 the blood of viremic diseased cats compared to viremic healthy cats. Because FeLV

10 p27 levels in the blood may be easily determined by quantitative p27 ELISA,

11 following this parameter in persistently infected cats over time may be a predictor of

12 imminent, FeLV-associated, fatal disease and thus helpful to practitioners and cat

13 owners.

14 Compared to viremic cats, cats with regressive infection survived even longer and did

15 not develop FeLV-associated disease. Three of the five cats from the regressive group

16 were infected with FeLV for more than 12 years prior to the end of the experiment

17 (Table 2). During the final 6.2 years of the study, they lived in a cohort of only

18 provirus-positive, but $\mathrm{p} 27$-negative cats. Thus, although these cats had definitely not

19 been re-exposed to FeLV for over 6 years, FeLV was still detectable in most of their

20 tissues. It has been postulated that the provirus continuously boosts the FeLV-specific

21 immune response in these cats [4]. Indeed, some of these cats showed high anti-FeLV

22 antibody levels, even many years after FeLV exposure (KHH unpublished

23 observations).

24 In the present study, several cats with regressive FeLV infection showed reactivation

25 of FeLV infection during the observation period. Most tissue samples from 
1 reactivated cats showed intermediate viral RNA and provirus tissue loads, with loads

2 between those of the cats with regressive and persistent infection. It must therefore be

3 assumed that the tissue loads of regressively infected cats increased prior to or upon

4 reactivation of the virus. This hypothesis could be addressed in a future, prospective

5 experiment using repeated fine needle aspirates from organs (e.g., lymph nodes) or a

6 collection of bone marrow samples from cats with regressive infection over time to

7 evaluate tissue loads as a predictive factor of the outcome of infection (i.e., imminent

8 reactivation).

9 Viral RNA and provirus loads varied significantly between the different tissues that

10 were analyzed, with the highest loads in the lymphatic tissues, intestinal tract and

11 salivary glands. The high viral RNA loads that were measured in lymphoid tissues

12 indicate that leukocytes are a target of infection and a site of replication, as described

13 previously [8-11]. The other tissues that showed high viral RNA loads all contained

14 mucosal or glandular epithelial tissues, which seemed to be favored sites of viral

15 replication. It should be noted that the tissues might have contained some FeLV

16 provirus and viral RNA due to the blood supply in the tissues. High blood loads may

17 particularly be expected in viremic cats, and lower loads may be expected in

18 regressive cats $[4,6,20,26,54]$. It would have been helpful to measure the blood

19 loads in the individual cats so that the copy numbers due to blood supply could have

20 been calculated as suggested, e.g., for bacterial hemoplasma infections [55].

21 Unfortunately, no terminal blood samples were available for these analyses.

22 Interestingly, a strong correlation was found between the viral RNA and provirus

23 loads in tissues from cats $(r=0.843, \mathrm{p}<0.0001)$. A similar observation has been

24 described for the viral RNA and provirus loads in the blood during the course of

25 experimental FeLV infection $[19,56]$. In addition, it has been shown that the FeLV 
1 provirus load in peripheral blood correlates with the disease outcome in experimental

2 FeLV infection [18, 26, 56]. In the study of Hofmann-Lehmann and colleagues

3 (2001), a comparison of provirus loads and p27 antigen status in blood samples from

4597 Swiss cats was performed. A 300-fold higher mean provirus load was found in

5 cats testing positive for $\mathrm{p} 27$ antigen and provirus compared to cats testing negative for

6 p27 and positive for provirus. A later comparison of the response categories in

7 experimentally infected cats revealed that in the first week after infection, regressive

8 and viremic cats had similar provirus and viral RNA loads, whereas the results from

9 later time points were in agreement with our findings for tissue samples of 1,000- to

1010,000 fold differences between the categories [26]. Thus, the association between

11 FeLV provirus load in blood and outcome of infection can now be shown for viral

12 RNA and provirus loads in tissue and outcome of infection.

13 The investigation was conducted as a retrospective study, including several cats which

14 had been vaccinated previously. Earlier studies have shown that even effective

15 vaccines do not lead to sterilizing immunity and that the FeLV loads in successfully

16 vaccinated cats resemble those of cats with naturally contained infection. Moreover,

17 cats that were not protected by vaccination from progressive infection showed the

18 same infection outcome as unvaccinated cats with progressive infection $[4,5]$. The

19 influence of the vaccine is thus mainly within the first days or weeks after virus

20 exposure, when either a contained or progressive infection will prevail; eight weeks

21 after infection the outcome of infection is established [20] - and most likely not

22 influenced by the vaccine anymore. Nonetheless, we compared the duration of FeLV-

23 infection in persistently viremic cats in the current study between vaccinated and non-

24 vaccinated cats. No significant difference could be detected $\left(p_{\mathrm{MWU}}=0.4580\right)$. 
1 Interestingly, reactivation of FeLV infection was observed in several cats reported

2 herein, including cats that were never positive for $\mathrm{p} 27$, and in virus isolation from the

3 blood or bone marrow at the tested time points. However, it cannot be excluded that

4 some positive time points were missed, because cats were usually only sampled

5 weekly. Previously, it had been hypothesized that the persistence of plasma viral RNA

6 in cats with regressive infection might be a prognostic marker for subsequent

7 reactivation; the viral RNA might have originated from minimal viral replication in a

8 sequestered tissue [26]. In the current study, blood samples for RNA determination

9 were only available from the first 15 weeks of infection. Analysis of these samples

10 showed that plasma viral RNA loads in cats with regressive infection were lower than

11 those of viremic cats but higher than in regressive cats that did not reactivate infection

12 (data not shown).

13 The time point of reactivation is one of the interesting features of cats with regressive

14 infection. Although the five cats showing reactivation in the present study had been

15 experimentally infected with FeLV-A/Glasgow-1, they were clinically healthy until

16 shortly before reactivation. The duration of infection until reactivation was highly

17 variable among the different cats and ranged from 0.5 to 1.9 years $[4,26,40,43]$, not

18 including a FIV-coinfected cat, which reactivated infection 8.5 years after the FeLV

19 exposure/infection [36]. The trigger for virus reactivation could not be determined

20 because these cats had not undergone a stressful procedure nor had they been immune

21 suppressed, with the exception of the FIV-infected cat [36]. The differences between

22 the p27 levels that were detected at the time of euthanasia might be explained by the

23 time point chosen for their euthanasia.

24 We included several cats that developed lymphoma after experimental FeLV-

25 A/Glasgow-1 infection. Cats are believed to be the species with the highest incidence 
1 of lymphoma [57], with approximately $22 \%$ of FeLV-antigen positive cats developing

2 lymphomas [58]. Due to mass testing, elimination and quarantine programs as well as

3 the broad usage of FeLV vaccines, the estimates of the prevalence of FeLV-associated

4 types of lymphomas have decreased [57]. We speculated whether tumor tissue from

5 persistently FeLV-infected cats might be experiencing higher loads of FeLV than

6 non-tumor tissue. The tissue loads previously described in one cat with reactivated

7 infection, suggested higher loads in tumor tissues of a multicentric lymphoma

8 compared to non-tumor tissues [36]. However, in that study, no comparison between

9 tumor and non-tumor tissue within the same organ was possible. Our results show no

10 statistically significant differences between viral RNA and provirus loads of tumor

11 and the respective non-tumor tissue (data not shown, $\mathrm{n}=10$ for viral RNA, $\mathrm{n}=13$ for

12 provirus). This may indicate that not difference in viral RNA or provirus loads are

13 associated with the induction of lymphomas but that other mechanisms, such as

14 activating cellular oncogenes at the site of provirus integration, might be sufficient to

15 induce lymphoma [59].

\subsection{Conclusions}

18 Determination of viral RNA and provirus loads in tissues of FeLV-infected cats

19 provided valuable information toward a better understanding of pathogenesis and

20 infection outcome. Moreover, these results add new evidence concerning the question

21 whether FeLV can be cleared by the immune system of the host over time.

22 Remarkably, FeLV was detectable in the majority of tissues from regressive cats in

23 the present study, demonstrating persistence of FeLV, even many years after virus

24 exposure. We assume that the virus maintains the potential for replication, because

25 provirus as well as viral RNA was found in these cats. The immune system of cats 
1 with regressive infection continuously and effectively suppresses viral replication to a

2 minimum. Should the immune system fail, the infection may reactivate, even many

3 years after FeLV exposure, as had been demonstrated in the exceptional case of a cat

4 co-infected with FIV 8.5 years after FeLV infection. Future studies should further

5 characterize the immune response that keeps this retrovirus infection successfully and

6 persistently in check, particularly of cats with regressive infection.

8 Competing interests

9 The authors declare that they have no conflicts of interest.

\section{Authors' contributions}

11 AKH performed and analyzed the research and drafted the manuscript. SW and YK

12 performed the virus and provirus quantifications. BR was responsible for housing and 13 care of the animals. FSB was responsible for all clinical aspects of the project. PG

14 performed the necropsy, macroscopic and histological analysis and the sample

15 collection. HL had initiated, directed and supported some of the experimental studies.

16 RHL conceived and supervised the follow-up study and edited the manuscript.

\section{Acknowledgements}

18 We would especially like to thank Dr. ML Meli for excellent assistance and helpful

19 discussions. We are grateful to the animal caretakers for expert technical aid with the

20 cats and the technicians and doctoral students of the Clinical Laboratory, particularly

21 B. Weibel and T. Meili Prodan, for excellent laboratory assistance. The molecular

22 biology work was performed using the logistics of the Center for Clinical Studies,

23 Vetsuisse Faculty, University of Zurich.

24 The work was supported by a research grant of the Swiss National Science

25 Foundation (310030_135586). 


\section{References}

2 1. Hoover EA, Mullins JI: Feline leukemia virus infection and diseases.

2. Marciani DJ, Kensil CR, Beltz GA, Hung CH, Cronier J, Aubert A: Journal of American Veterinary Medical Association 1991, 199(10):12871297. Genetically-engineered subunit vaccine against feline leukaemia virus: protective immune response in cats. Vaccine 1991, 9(2):89-96.

3. Hines DL, Cutting JA, Dietrich DL, Walsh JA: Evaluation of efficacy and safety of an inactivated virus vaccine against feline leukemia virus infection. Journal of American Veterinary Medical Association 1991, 199(10):1428-1430.

4. Hofmann-Lehmann R, Tandon R, Boretti FS, Meli ML, Willi B, Cattori V, Gomes-Keller MA, Ossent P, Golder MC, Flynn JN et al: Reassessment of feline leukaemia virus (FeLV) vaccines with novel sensitive molecular assays. Vaccine 2006, 24(8):1087-1094.

5. Lehmann R, Franchini M, Aubert A, Wolfensberger C, Cronier J, Lutz H: Vaccination of cats experimentally infected with feline immunodeficiency virus, using a recombinant feline leukemia virus vaccine. Journal of the American Veterinary Medical Association 1991, 199(10):1446-1452.

6. Torres AN, O'Halloran KP, Larson LJ, Schultz RD, Hoover EA: Feline leukemia virus immunity induced by whole inactivated virus vaccination. Vet Immunol Immunopathol 2010, 134(1-2):122-131.

7. Jarrett WF, Crawford EM, Martin WM, Davie F: A virus-like particle associated with leukaemia (lymphosarcoma). Nature 1964, 202:567-568.

8. Hoover EA, Olsen RG, Mathes LE, Schaller JP: Relationship between feline leukemia virus antigen expression and viral infectivity in blood, bone marrow, and saliva of cats. Cancer Research 1977, 37:3707-3710.

9. Hoover EA, Olsen RG, Hardy WD, Jr., Schaller JP, Mathes LE, Cockerell GL: Biologic and immunologic response of cats to experimental infection with feline leukemia virus. BiblHaematol 1975(43):180-183.

10. Rojko JL, Hoover EA, Mathes LE, Olsen RG, Schaller JP: Pathogenesis of experimental feline leukemia virus infection. J Natl Cancer Inst 1979, 63(3):759-768.

11. Pepin AC, Tandon R, Cattori V, Niederer E, Riond B, Willi B, Lutz H, Hofmann-Lehmann R: Cellular segregation of feline leukemia provirus and viral RNA in leukocyte subsets of long-term experimentally infected cats. Virus Res 2007, 127(1):9-16.

12. Cattori V, Pepin AC, Tandon R, Riond B, Meli ML, Willi B, Lutz H, Hofmann-Lehmann R: Real-time PCR investigation of feline leukemia 
13. Lutz H, Pedersen NC, Theilen GH: Course of feline leukemia virus infection and its detection by enzyme-linked immunosorbent assay and monoclonal antibodies. American Journal of Veterinary Research 1983, 44(11):20542059.

14. Gomes-Keller MA, Gonczi E, Grenacher B, Tandon R, Hofman-Lehmann R, Lutz H: Fecal shedding of infectious feline leukemia virus and its nucleic acids: a transmission potential. Vet Microbiol 2009, 134(3-4):208-217.

15. Pacitti AM, Jarrett $O$, Hay D: Transmission of feline leukaemia virus in the milk of a non-viraemic cat. Vet Rec 1986, 118(14):381-384.

16. Cattori V, Tandon R, Riond B, Pepin AC, Lutz H, Hofmann-Lehmann R: The kinetics of feline leukaemia virus shedding in experimentally infected cats are associated with infection outcome. Vet Microbiol 2009, 133(3):292-296.

17. Cattori V, Hofmann-Lehmann R: Absolute quantitation of feline leukemia virus proviral DNA and viral RNA loads by TaqMan real-time PCR and RT-PCR. Methods Mol Biol 2008, 429:73-87.

18. Hofmann-Lehmann R, Huder JB, Gruber S, Boretti F, Sigrist B, Lutz H: Feline leukaemia provirus load during the course of experimental infection and in naturally infected cats. J Gen Virol 2001, 82(Pt 7):15891596.

19. Tandon R, Cattori V, Gomes-Keller MA, Meli ML, Golder MC, Lutz H, Hofmann-Lehmann R: Quantitation of feline leukaemia virus viral and proviral loads by TaqMan real-time polymerase chain reaction. J Virol Methods 2005, 130(1-2):124-132.

20. Torres AN, Mathiason CK, Hoover EA: Re-examination of feline leukemia virus: host relationships using real-time PCR. Virology 2005, 332(1):272283.

21. Lutz H, Pedersen N, Higgins J, Hubscher U, Troy FA, Theilen GH: Humoral immune reactivity to feline leukemia virus and associated antigens in cats naturally infected with feline leukemia virus. Cancer Research 1980, 40(10):3642-3651.

22. Pedersen NC, Theilen G, Keane MA, Fairbanks L, Mason T, Orser B, Che $\mathrm{CH}$, Allison C: Studies of naturally transmitted feline leukemia virus infection. American Journal of Veterinary Research 1977, 38(10):1523-1531.

23. Hardy WD, Jr., Hess PW, MacEwen EG, McClelland AJ, Zuckerman EE, Essex M, Cotter SM, Jarrett O: Biology of feline leukemia virus in the natural environment. Cancer Research 1976, 36(2 pt 2):582-588.

24. Rojko JL, Hoover EA, Mathes LE, Hause WR, Schaller JP, Olsen RG: Detection of feline leukemia virus in tissues of cats by a paraffin 
embedding immunofluorescence procedure. Journal of National Cancer Institute 1978, 61:1315-1321.

25. Torres AN, O'Hallorant KP, Larson L, Schultz RD, Hoover EA: Insight into FeLV:host relationship using real-time DNA and RNA qPCR. In: 8th International Feline Retrovirus Research Symposium: October 8-11, 2006 2006; Washington, DC; 2006: 50.

26. Hofmann-Lehmann R, Cattori V, Tandon R, Boretti FS, Meli ML, Riond B, Pepin AC, Willi B, Ossent P, Lutz H: Vaccination against the feline leukaemia virus: outcome and response categories and long-term followup. Vaccine 2007, 25(30):5531-5539.

27. Major A, Cattori V, Boenzli E, Riond B, Ossent P, Meli ML, HofmannLehmann R, Lutz H: Exposure of cats to low doses of FeLV:

seroconversion as the sole parameter of infection. Vet Res 2010, 41(2):17.

28. Jarrett W, Mackey L, Jarrett O, Laird H, Hood C: Antibody response and virus survival in cats vaccinated against feline leukaemia. Nature 1974, 248:230-232.

29. Essex M, Hardy WD, Jr., Cotter SM, Jakowski RM: Immune response of healthy and leukemic cats to the feline oncornavirus-associated cell membrane antigen. BiblHaematol 1975:483-488.

30. Jarrett O, Russell PH, Stewart MF: Protection of kittens from feline leukaemia virus infection by maternally-derived antibody. Veterinary Record 1977, 101:304-305.

31. Flynn JN, Hanlon L, Jarrett O: Feline leukaemia virus: protective immunity is mediated by virus-specific cytotoxic T lymphocytes. Immunology 2000, 101(1): 120-125.

32. Hofmann-Lehmann R, Cattori V, Tandon R, Boretti FS, Meli ML, Riond B, Lutz H: How molecular methods change our views of FeLV infection and vaccination. Vet Immunol Immunopathol 2008, 123(1-2):119-123.

33. Hardy WD, Jr., McClelland AJ, Zuckerman EE, Hess PW, Essex M, Cotter SM, MacEwen EG, Hayes AA: Prevention of the contagious spread of feline leukaemia virus and the development of leukaemia in pet cats. Nature 1976, 263:326-328.

34. Flynn JN, Dunham SP, Watson V, Jarrett O: Longitudinal analysis of feline leukemia virus-specific cytotoxic $\mathbf{T}$ lymphocytes: correlation with recovery from infection. J Virol 2002, 76(5):2306-2315.

35. McClelland AJ, Hardy WD, Zuckerman EE: Prognosis of healthy feline leukemia virus infected cats. In: Development in Cancer Research. Edited by Hardy WD, Essex M, McClelland AJ, vol. 4. Amsterdam: Elsevier Scientific Publishing Company; 1980: 121-126. 
36. Helfer-Hungerbuehler AK, Cattori V, Boretti FS, Ossent P, Grest P, Reinacher M, Henrich M, Bauer E, Bauer-Pham K, Niederer E et al: Dominance of highly divergent feline leukemia virus A progeny variants in a cat with recurrent viremia and fatal lymphoma. Retrovirology 2010, 7(1):14.

37. Pedersen NC, Meric SM, Johnson L, Plucker S, Theiler GH: The clinical significance of latent feline leukemia virus infection in cats. Feline Pratice 1984, 14:32-48.

38. Rojko JL, Hoover EA, Quackenbush SL, Olsen RG: Reactivation of latent feline leukaemia virus infection. Nature 1982, 298(5872):385-388.

39. Post JE, Warren L: Reactivation of latent feline leukemia virus. In: Feline Leukemia Virus. Edited by Hardy Jr. WD, Essex M, McClelland AJ. New York: Elsevier North Holland Inc.; 1980: 151-155.

40. Boesch A, Cattori V, Riond B, Willi B, Meli ML, Rentsch KM, Hosie MJ, Hofmann-Lehmann R, Lutz H: Evaluation of the effect of short-term treatment with the integrase inhibitor raltegravir (Isentress) on the course of progressive feline leukemia virus infection. Vet Microbiol 2014.

41. Geret CP, Cattori V, Meli ML, Riond B, Martinez F, Lopez G, Vargas A, Simon MA, Lopez-Bao JV, Hofmann-Lehmann R et al: Feline leukemia virus outbreak in the critically endangered Iberian lynx (Lynx pardinus): high-throughput sequencing of envelope variable region $A$ and experimental transmission. Arch Virol 2011.

42. Tandon R, Cattori V, Pepin AC, Riond B, Meli ML, McDonald M, Doherr MG, Lutz H, Hofmann-Lehmann R: Association between endogenous feline leukemia virus loads and exogenous feline leukemia virus infection in domestic cats. Virus Res 2008, 135(1):136-143.

43. Nesina S: Transmission of Feline Leukemia Virus Infection by Provirus Positive Blood. Inaugural disseration. Zurich: University of Zurich; 2013.

44. Valli VE: Lymphoproliferative Diseases, in: Veterinary Comparative Hematopathology, 1st edn: Wiley-Blackwell; 2007.

45. Lutz H, Pedersen NC, Durbin R, Theilen GH: Monoclonal antibodies to three epitopic regions of feline leukemia virus p27 and their use in enzyme-linked immunosorbent assay of p27. Journal of Immunological Methods 1983, 56(2):209-220.

46. Jarrett O, Ganiere JP: Comparative-studies of the efficacy of a recombinant feline leukemia virus vaccine. Veterinary Record 1996, 138(1):7-11.

47. Kessler Y, Helfer-Hungerbuehler AK, Cattori V, Meli ML, Zellweger B, Ossent P, Riond B, Reusch CE, Lutz H, Hofmann-Lehmann R: Quantitative TaqMan real-time PCR assays for gene expression normalisation in feline tissues. BMC Mol Biol 2009, 10:106. 


\section{Helfer-Hungerbuehler AK, Widmer S, Hofmann-Lehmann R: GAPDH Pseudogenes and the Quantification of Feline Genomic DNA Equivalents.}

50. Hofmann-Lehmann R, Holznagel E, Ossent P, Lutz H: Parameters of disease

51. Chandhasin C, Coan PN, Pandrea I, Grant CK, Lobelle-Rich PA, Puetter A, Levy LS: Unique long terminal repeat and surface glycoprotein gene sequences of feline leukemia virus as determinants of disease outcome. $J$ Virol 2005, 79(9):5278-5287.

52. Phipps AJ, Chen H, Hayes KA, Roy-Burman P, Mathes LE: Differential pathogenicity of two feline leukemia virus subgroup A molecular clones, pFRA and pF6A. $J$ Virol 2000, 74(13):5796-5801.

53. Levy J, Crawford C, Hartmann K, Hofmann-Lehmann R, Little S, Sundahl E, Thayer V: 2008 American Association of Feline Practitioners' feline retrovirus management guidelines. J Feline Med Surg 2008.

54. Gomes-Keller MA, Tandon R, Gonczi E, Meli ML, Hofmann-Lehmann R, Lutz $\mathrm{H}$ : Shedding of feline leukemia virus RNA in saliva is a consistent feature in viremic cats. Vet Microbiol 2006, 112(1):11-21.

55. Tasker S, Peters IR, Day MJ, Willi B, Hofmann-Lehmann R, Gruffydd-Jones TJ, Helps CR: Distribution of Mycoplasma haemofelis in blood and tissues following experimental infection. Microb Pathog 2009, 47(6):334-340.

56. Torres AN, O'Halloran KP, Larson LJ, Schultz RD, Hoover EA: Development and application of a quantitative real-time PCR assay to detect feline leukemia virus RNA. Veterinary Immunology and Immunopathology 2008, 123(1-2):81-89.

57. Louwerens M, London CA, Pedersen NC, Lyons LA: Feline lymphoma in the post-feline leukemia virus era. $J$ Vet Intern Med 2005, 19(3):329-335.

58. Reinacher M: Diseases associated with spontaneous feline leukemia virus (FeLV) infection in cats. Vet Immunol Immunopathol 1989, 21(1):85-95.

59. Weiss AT, Klopfleisch R, Gruber AD: Prevalence of feline leukaemia provirus DNA in feline lymphomas. Journal of Feline Medicine and Surgery 2010, 12(12):929-935. 


\section{Figures}

2 Figure 1 - FeLV p27 antigen, viral RNA and provirus loads in cats with 3 different infection outcome.

4 A) Comparison of FeLV p27 antigen levels in the different FeLV response categories as determined by ELISA. B) Time course of FeLV infection in cats with reactivation after regressive infection. Comparison of the FeLV viral RNA load (C) and provirus load (D) in tissues from cats of different response categories. A) and B) Results are represented as percentages of a defined positive control (plasma sample from a persistently FeLV-infected cat), which was considered 100\%. Samples reaching > 4\% of the positive control signal were considered positive [4]. FeLV p27 antigen levels whiskers extend from the smallest to the largest value.

Figure 2 - FeLV viral RNA loads in tissues from cats in different FeLV response categories.

18 The FeLV viral RNA loads in 27 different tissues collected during necropsy from

19 FeLV-infected cats in four response categories were quantified using real-time RT-

PCR: A) regressive cats, B) cats with reactivated infection, C) viremic healthy cats

21 and D) viremic ill cats. The FeLV viral RNA load was normalized to the reference gene RPS7. Similar results have been obtained with normalization to the copies of GAPDH cDNA (data not shown). The data are shown as box plots, and the boxes extend from the $25^{\text {th }}$ to $75^{\text {th }}$ percentiles. The horizontal line represents the median, and the whiskers extend from the smallest to the largest value. The grey shading in the boxes indicates the presence of a complete dataset (4-5 independent samples for each tissue), light grey lines indicate missing values. FeLV viral RNA loads were tested for 
1 significant differences by the non-parametric Friedmann test $\left(p_{\mathrm{F}}\right)$, including only

2 paired samples and the Dunn's Multiple Comparison test: * $=\mathrm{p}<0.05 ; * *=\mathrm{p}<0.01$;

$3 * * *=\mathrm{p}<0.001$.

Figure 3 - FeLV viral RNA loads in different functional groups of tissues and in single tissues.

6 Comparison of FeLV viral RNA loads among different response categories in A) the

7 salivary glands (parotid and mandibular gland), B) the urinary tract (including the urinary bladder and the kidney), C) the mandibular gland and D) the urinary bladder. The FeLV viral RNA copy numbers are normalized to RPS7 cDNA copies. Similar results have been obtained with normalization to GAPDH cDNA copies (data not

11 shown). The data are shown as box plots, and the boxes extend from the $25^{\text {th }}$ to $75^{\text {th }}$

12 percentiles. The horizontal line represents the median, and the whiskers extend from 13 the smallest to the largest value. FeLV viral RNA loads were tested for significant 14 differences by Kruskal-Wallis one-way ANOVA by Ranks ( $p_{\mathrm{KW}}$ as indicated) and 15 subsequently by Dunn's post test: $*=\mathrm{p}<0.05 ; * *=\mathrm{p}<0.01 ; * * *=\mathrm{p}<0.001$.

\section{Figure 4 - FeLV provirus loads in tissues from different FeLV response categories.}

The FeLV provirus loads in 27 different tissues collected during necropsy from

FeLV-infected cats grouped into four response categories were quantified using realtime PCR: A) regressive cats, B) reactivated cats, C) viremic healthy cats and D) viremic ill cats. The FeLV provirus load was normalized using fALB. The data are shown as box plots, and the boxes extend from the $25^{\text {th }}$ to $75^{\text {th }}$ percentiles. The horizontal line represents the median, and the whiskers extend from the smallest to the largest value. The grey shading indicates the presence of a complete dataset $(\geq 4$ independent samples for each tissue), and light grey lines indicate missing values. FeLV provirus loads were tested for significant differences by the non-parametric 
1 Friedmann test $\left(p_{\mathrm{F}}\right)$ including only paired samples and the Dunn's Multiple

2 Comparison test: $*=\mathrm{p}<0.05 ; * *=\mathrm{p}<0.01 ; * * *=\mathrm{p}<0.001$.

3 Figure 5 - FeLV provirus loads in different functional groups of tissues and in 4 single tissues.

5 The FeLV provirus loads among the different response categories were compared in

6 the A) salivary glands (parotid and mandibular gland), B) urinary tract (including the

7 urinary bladder and the kidney), C) mandibular gland and D) urinary bladder. The

8 FeLV provirus copy numbers were normalized to fALB. The data are shown as box

9 plots, and the boxes extend from the $25^{\text {th }}$ to $75^{\text {th }}$ percentiles. The horizontal line

10 represents the median, and the whiskers extend from the smallest to the largest value.

11 FeLV provirus loads were tested for significant differences by Kruskal-Wallis one-

12 way ANOVA by Ranks ( $p_{\mathrm{KW}}$ as indicated) and subsequently by Dunn's post test: $*=$

$13 \mathrm{p}<0.05 ; * *=\mathrm{p}<0.01 ; * * *=\mathrm{p}<0.001$. 


\section{Tables}


Table 1 - Duration and outcome of experimental FeLV infection in persistently viremic cats (FeLV-A/Glasgow-1)

\begin{tabular}{|c|c|c|c|c|c|}
\hline Cat ID & $\begin{array}{l}\text { Age at infection } \\
\text { (weeks) }\end{array}$ & $\begin{array}{l}\text { Terminal age } \\
\text { (years) }\end{array}$ & $\begin{array}{l}\text { Infection duration } \\
\text { (years) }\end{array}$ & Major diagnosis at necropsy & Reference \\
\hline \#HBZ3 & 10 & 1.8 & 1.6 & Lymphoma $\left(\mathrm{CD}^{+}\right.$; $\left.\mathrm{CD}^{2} \mathrm{a}^{-}\right)$in thymus, pericard, tonsils, and prescapular $\ln$. & {$[43]^{2}$} \\
\hline \#17 & 19 & 2.0 & 1.7 & Lymphoma in mesenteric ln., intestines, liver, spleen, diaphragm, kidney & {$[4]^{2}$} \\
\hline \#27 & 18 & 2.3 & 2.0 & Lymphoma in the thymus, pericard and various $\ln$. & {$[4]^{2}$} \\
\hline$\# 67^{1}$ & 17 & 2.6 & 2.3 & Lymphoma in thymus, spleen, liver, various ln., and bm & {$[4]^{3}$} \\
\hline \#264 & 59 & 3.7 & 2.6 & Lymphoma in the intestines, including ln., spleen, kidney, and diaphragm & {$[5]^{2}$} \\
\hline \#B3 $3^{1}$ & 17 & 3.1 & 2.8 & Lymphoma in the kidney and ln. of the gastrointestinal tract & {$[42]^{2}$} \\
\hline \#B $1^{1}$ & 18 & 3.8 & 3.4 & $\begin{array}{l}\text { Lymphoma in liver, diaphragm, ovary, gall bladder, mesenterium, } \\
\text { peritoneum and uterus }\end{array}$ & {$[42]^{2}$} \\
\hline \#Y4 & 17 & 4.2 & 3.8 & Lymphoma in thymus & {$[42]^{2}$} \\
\hline \#287 & 58 & 4.9 & 3.8 & Lymphoma in the thymus, liver, bm, sporadic $\ln$. & {$[5]^{2}$} \\
\hline \#Y3 & 17 & 4.2 & 3.9 & Lymphoma (CD3 $\left.{ }^{-} \mathrm{CD}^{2} \mathrm{a}^{-}\right)$in liver, spleen, tonsils, and jejunum & {$[42]^{2}$} \\
\hline$\# 19^{1}$ & 19 & 4.5 & 4.1 & Lymphoma in thymus, jejunum, ileum, mesenteric ln., and liver & {$[4]^{3}$} \\
\hline$\# 32^{1}$ & 18 & 4.5 & 4.1 & Lymphoma in thymus, & {$[4]^{3}$} \\
\hline \#272 & 59 & 6.6 & 5.5 & Lymphoma in thymus, diaphragm, kidney, and mesenteric ln. & {$[5]^{2}$} \\
\hline \#283 & 58 & 7.6 & 6.5 & Lymphoma in kidney, liver, spleen, bm, several ln., anemia & {$[5]^{2}$} \\
\hline \#63 & 17 & 2.2 & 1.8 & Erythroleukemia & {$[4]^{2}$} \\
\hline \#M2 & 17 & 5.7 & 5.3 & Acute lymphoblastic leukemia & {$[42]^{2}$} \\
\hline \#276 & 59 & 6.4 & 5.3 & Acute myeloid leukemia & {$[5]^{2}$} \\
\hline \#HBW2 & 10 & 0.8 & 0.6 & Nonregenerative anemia & {$[43]^{2}$} \\
\hline \#25 & 19 & 1.0 & 0.6 & Nonregenerative anemia & {$[4]^{2}$} \\
\hline$\# 26$ & 18 & 1.4 & 1.1 & Nonregenerative anemia & {$[4]^{2}$} \\
\hline
\end{tabular}

${ }^{1}$ These cats were also included in the tissue load study; ${ }^{2}$ not vaccinated; ${ }^{3}$ vaccinated with a whole virus vaccine (Fel-O-Vax, Fort Dodge, Iowa, USA). 
Table 2 - Tissue load study: Long-term outcome of FeLV infection in 19 experimentally FeLV-A/Glasgow-1 infected cats

\begin{tabular}{|c|c|c|c|c|c|}
\hline Cat ID & Category & $\begin{array}{l}\text { Infection } \\
\text { duration }(y)\end{array}$ & $\begin{array}{l}\text { p27 at euthanasia } \\
(\%)^{1}\end{array}$ & Outcome & Reference \\
\hline \#68 & Regressive & $(2.5)^{2}$ & 0 & Clinically healthy (end of experiment) & {$[4]^{3}$} \\
\hline \#258 & Regressive & $(12.7)^{2}$ & 0 & Clinically healthy (end of experiment) & {$[5]^{4}$} \\
\hline \#260 & Regressive & $(12.7)^{2}$ & 0 & Clinically healthy (end of experiment, finding upon necropsy: hydrometra) & {$[5]^{4}$} \\
\hline \#271 & Regressive & $(12.7)^{2}$ & 0 & Clinically healthy (end of experiment) & {$[5]^{4}$} \\
\hline \#B9 & Regressive & $(4.5)^{2}$ & 0 & Unrelated to FeLV-infection (foreign object) & {$[42]^{3}$} \\
\hline$\# 30$ & Reactivated & 1.0 & 25 & Lymphoma in thymus & {$[4,26]^{5}$} \\
\hline \#GCN4 & Reactivated & 1.2 & 132 & Lymphoma in the thymus and inguinal $\ln .\left(\mathrm{CD}^{+} ; \mathrm{CD}^{-} \mathrm{a}^{-}\right)$ & {$[40]^{3}$} \\
\hline \#HBU1 & Reactivated & 0.5 & 113 & $\begin{array}{l}\text { Lymphoma }\left(\mathrm{CD}^{+} ; \mathrm{CD} 79 \mathrm{a}^{-}\right) \text {in thymus, mesenteric ln., liver, kidney \& bm with } \\
\text { secondary leukemia }\end{array}$ & {$[43]^{3}$} \\
\hline \#261 & Reactivated & 8.5 & 53 & Lymphoma in spleen, liver, kidney, ln., intestine, lung, etc. & {$[5,36]^{4}$} \\
\hline$\# 70$ & Reactivated & 1.9 & 100 & Lymphoma in the thymus, tonsil, spleen, kidney, various $\ln$. & {$[4,26]^{6}$} \\
\hline$\# 15$ & Viremic healthy & $(0.9)^{2}$ & 65 & Clinically healthy (end of experiment) & {$[4]^{6}$} \\
\hline \#23 & Viremic healthy & $(0.9)^{2}$ & 42 & Clinically healthy (end of experiment) & {$[4]^{6}$} \\
\hline \#64 & Viremic healthy & $(0.9)^{2}$ & 55 & Clinically healthy (end of experiment) & {$[4]^{5}$} \\
\hline \#R1 & Viremic healthy & $(0.4)^{2}$ & 39 & Clinically healthy (end of experiment) & {$[41]^{3}$} \\
\hline$\# 19$ & Viremic ill & 4.1 & 154 & Lymphoma around thymus, parts of the gastrointestinal tract, ln. \& liver, hydrothorax & {$[4]^{6}$} \\
\hline \#32 & Viremic ill & 4.1 & 207 & Lymphoma in thymus, hydrothorax, atelectasis & {$[4]^{6}$} \\
\hline \#67 & Viremic ill & 2.3 & 190 & Lymphoma in thymus, spleen, liver and various $\ln$. & {$[4]^{6}$} \\
\hline \#B1 & Viremic ill & 3.4 & 72 & Lymphoma in liver, diaphragm, ovary, gall bladder and uterus & {$[42]^{3}$} \\
\hline \#B3 & Viremic ill & 2.8 & 168 & Lymphoma in the kidney and $\ln$. of the gastrointestinal tract & {$[42]^{3}$} \\
\hline
\end{tabular}


${ }^{1}$ Values above $4 \%$ of the positive control were considered positive [4]; ${ }^{2}$ The duration of the infection in cats with regressive infection and viremic healthy cats at the end of the experiment (tissue collection) is listed; ${ }^{3}$ not vaccinated; ${ }^{4}$ vaccinated with a recombinant protein vaccine (Leucogen, Virbac, Glattbrugg, Switzerland); ${ }^{5}$ vaccinated with a recombinant canarypox-vectored vaccine (Purevax, Merial, Lyon, France); ${ }^{6}$ vaccinated with a whole-virus vaccine (Fel-O-Vax, Fort Dodge, Iowa, USA). 


\begin{tabular}{ll} 
Tissue Group & Tissue(s) \\
\hline Endocrine system & Thyroid \\
Lymphoid tissues & bm, mesenteric ln., popliteal ln., sternal ln., submandibular ln., \\
& spleen, tonsil, thymus \\
Salivary glands & Parotid gland, mandibular gland \\
Intestinal tract & Duodenum, ileum, jejunum, colon, rectum \\
Nervous system & Brain, sciatic nerve, spinal cord \\
Urinary tract & Kidney, urinary bladder \\
Muscle & Diaphragm, femoral muscle, myocardium \\
Others & Lung, liver, aorta
\end{tabular}

\section{Supplementary files}

Supplementary file 1 - FeLV p27 antigen during FeLV infection in plasma of cats with different infection outcome

Time course of FeLV infection in cats with A) regressive, B) viremic healthy and C) viremic ill infection. Results are represented as percentages of a defined positive control (plasma sample from a persistently FeLV-infected cat), which was considered 100\%. Samples reaching $>4 \%$ of the positive control signal were considered positive [4].

\section{Supplementary file 2 -Correlation between viral RNA and provirus loads.}

A) RNA and gDNA were extracted from tissue samples from 19 cats, and the viral RNA and DNA, respectively, were analysed by qPCR. A Spearman correlation was performed and indicated a strong correlation between viral RNA and DNA $(r=0.843, \mathrm{p}<0.0001)$.

B) The ratios between all viral RNA and provirus loads are depicted for the different response categories. The data are shown as box plots, and the boxes extend from the $25^{\text {th }}$ to 75 th percentiles. The horizontal line represents the median, and the whiskers extend from the smallest 
to largest value. Samples with undetectable loads were excluded from this analysis. Ratios were tested for significant differences by Kruskal-Wallis one-way ANOVA by Ranks ( $p_{\mathrm{KW}}$ as indicated) and subsequently by Dunn's post test: $*=\mathrm{p}<0.05 ; * *=\mathrm{p}<0.01 ; * * *=\mathrm{p}<0.001$. 
A.

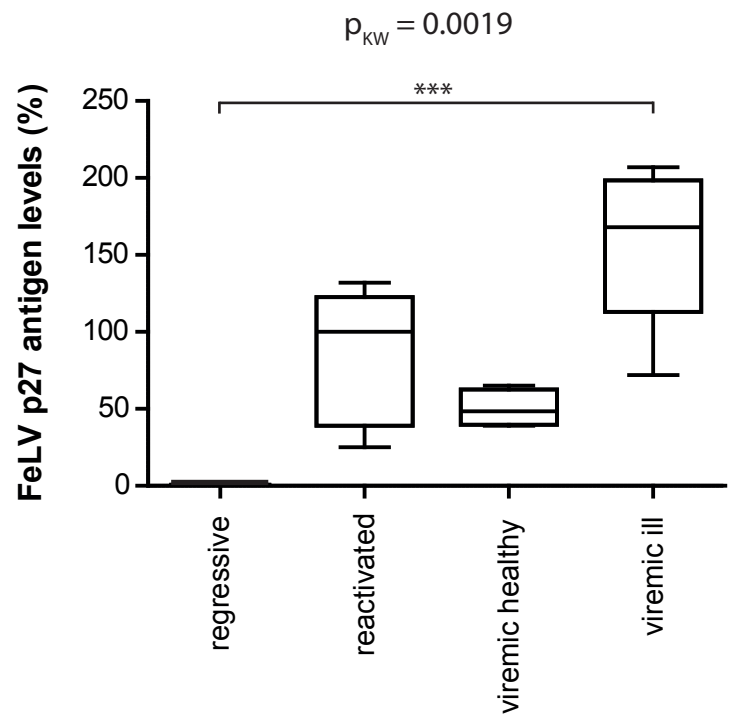

B.

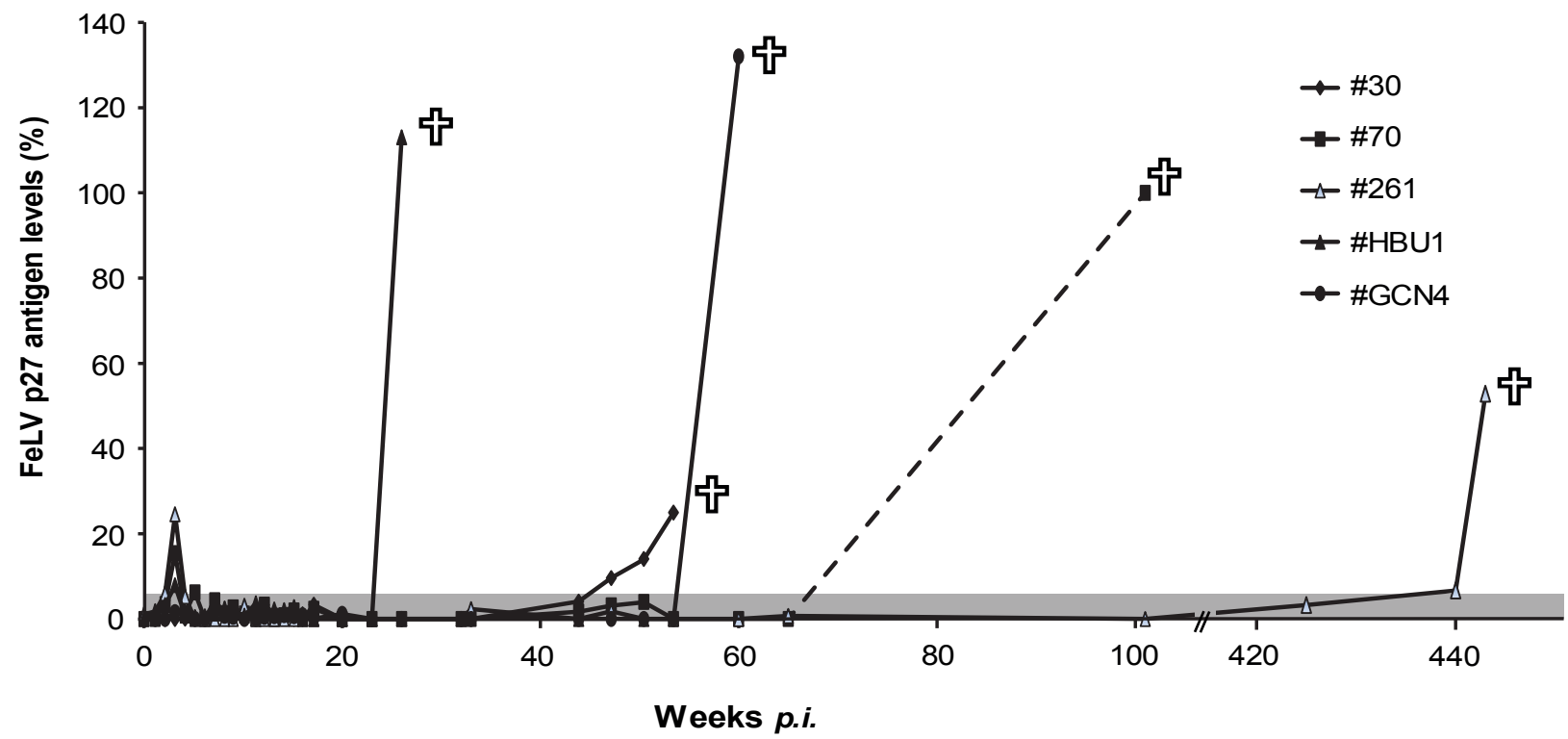

C.

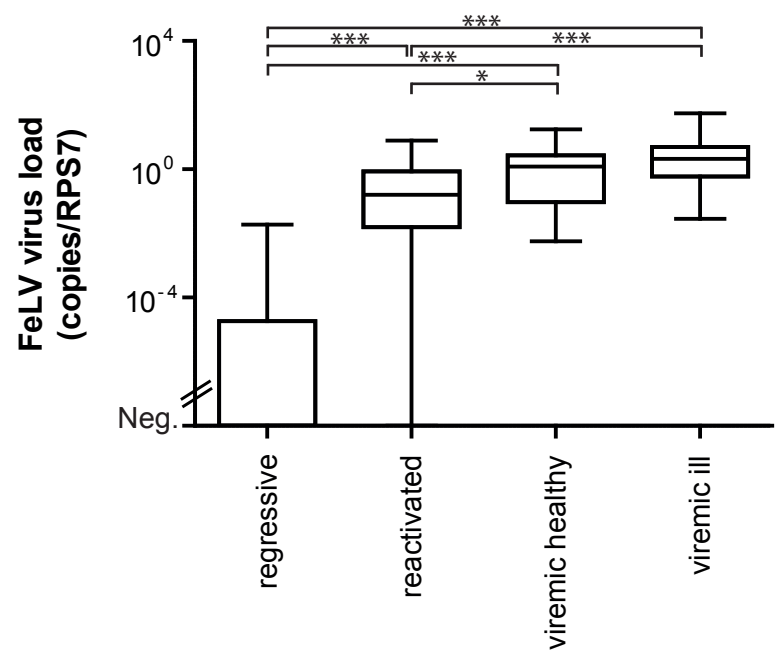

D.

$\mathrm{p}_{\mathrm{kW}}<0.0001$

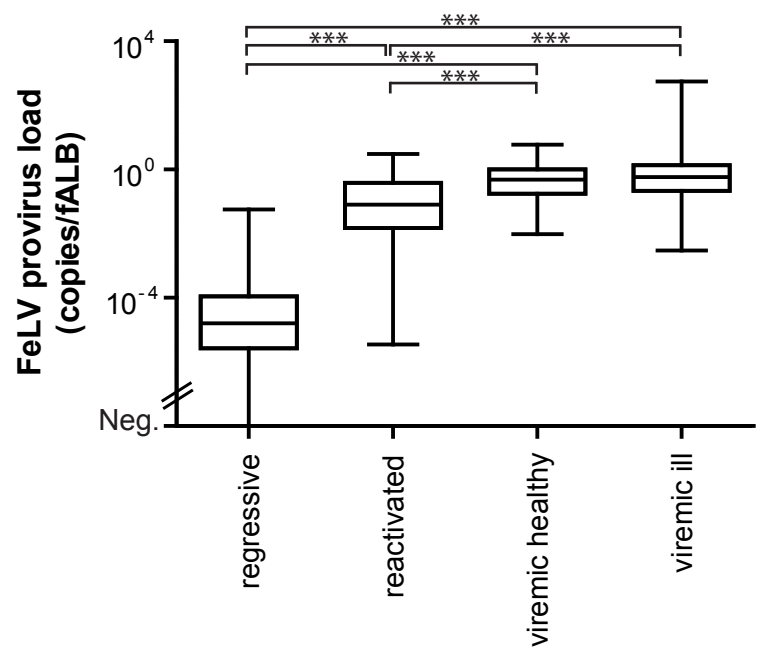

Figure 1_K. Helfer-Hungerbuehler et al., 2014 
A

B
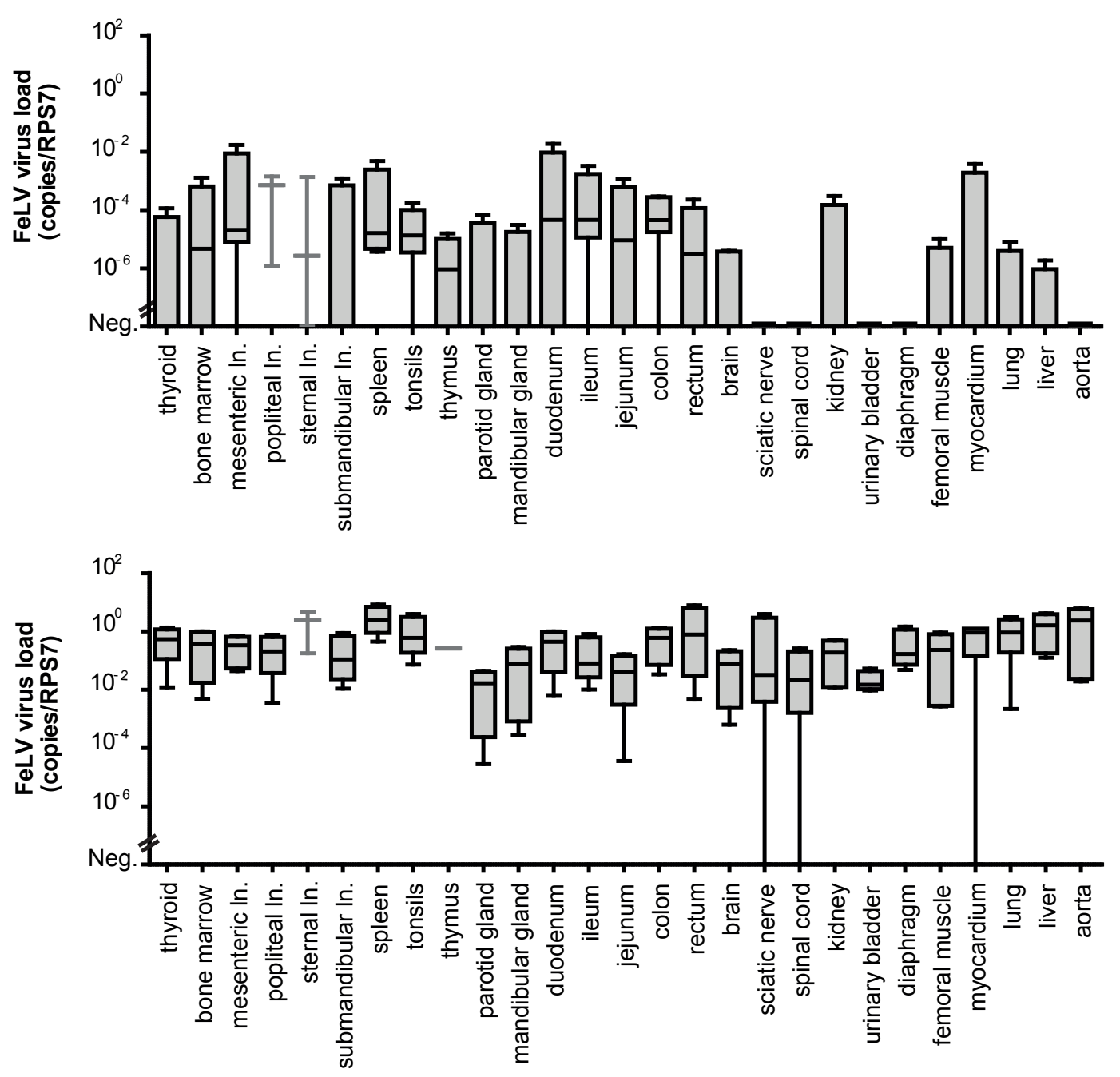

C

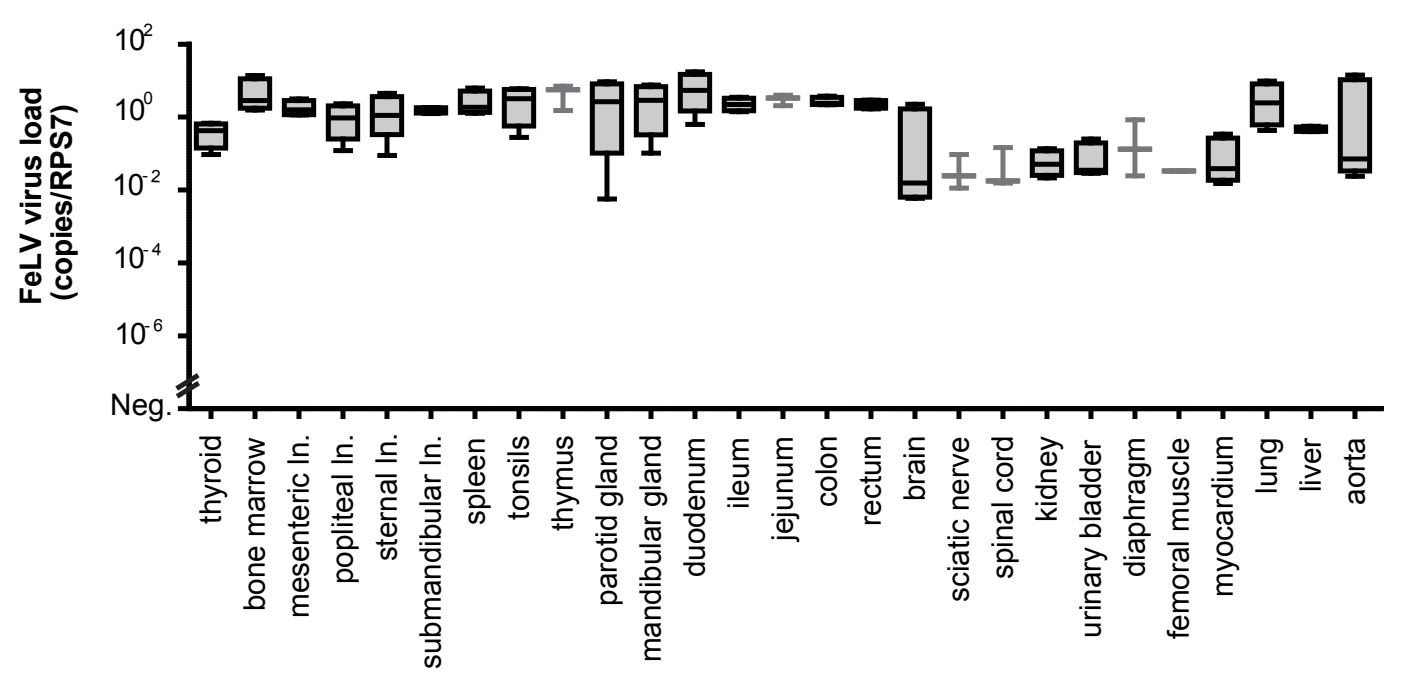

D

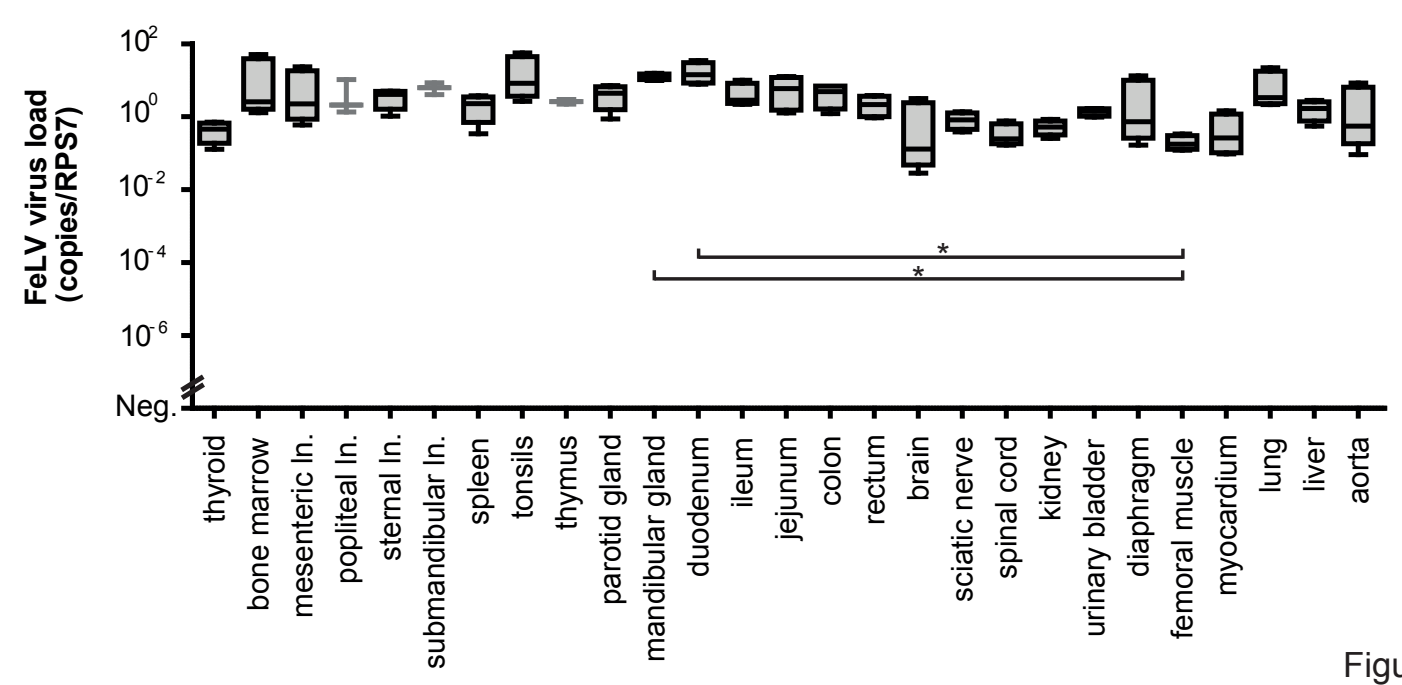


A

$$
p_{\mathrm{KW}}<0.0001
$$

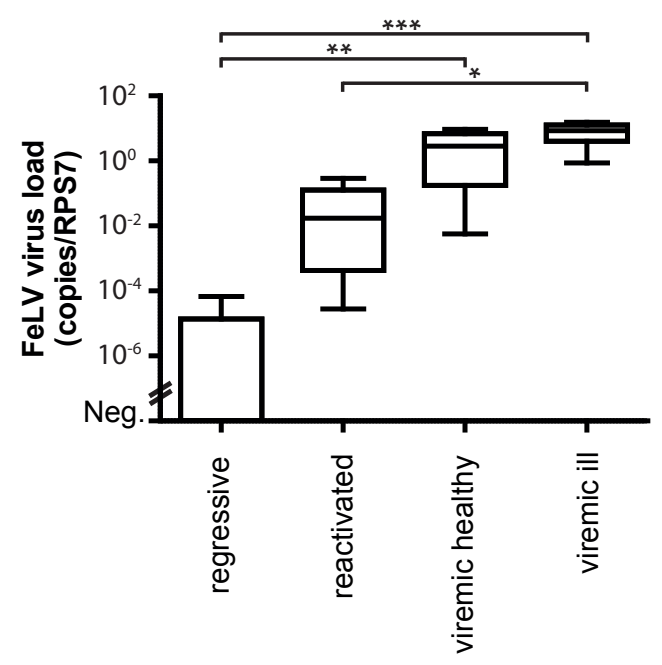

Cat group

C

$$
p_{\mathrm{kW}}=0.0023
$$

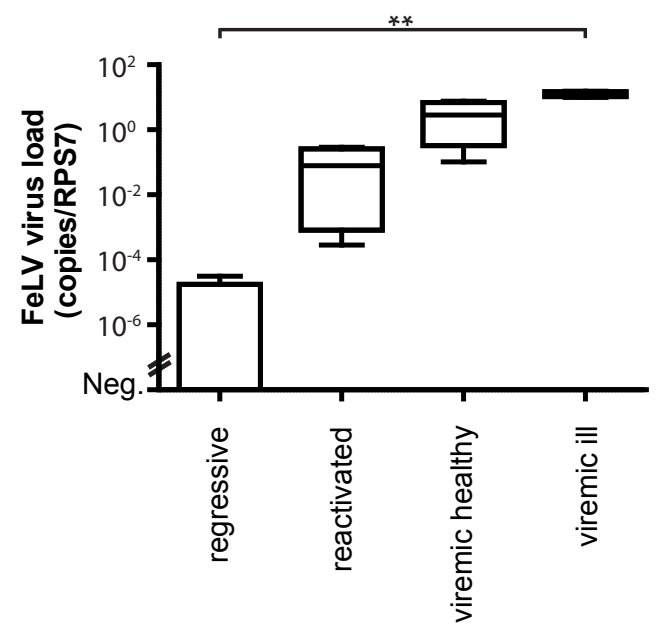

Cat group
B

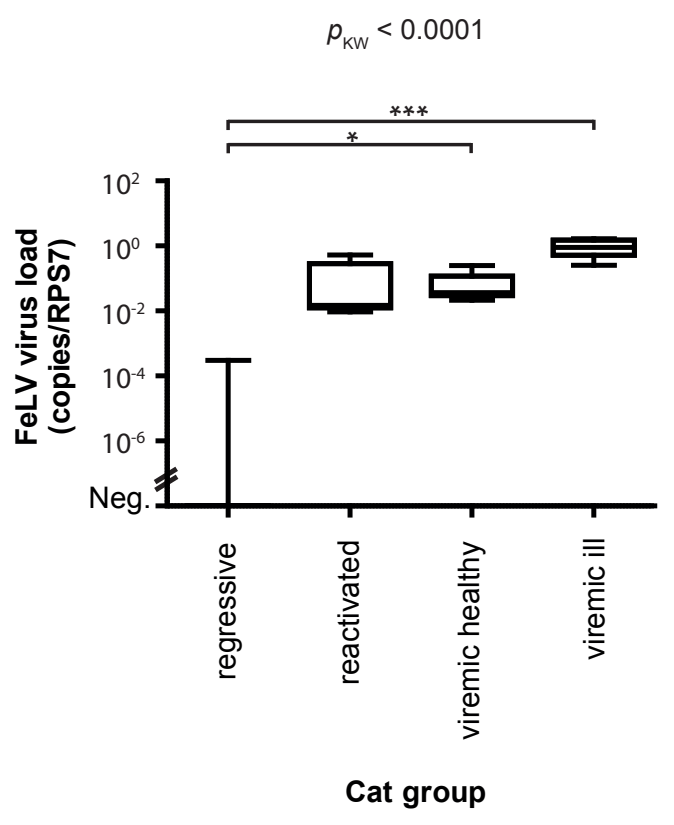

D

$$
p_{\mathrm{KW}}=0.0022
$$

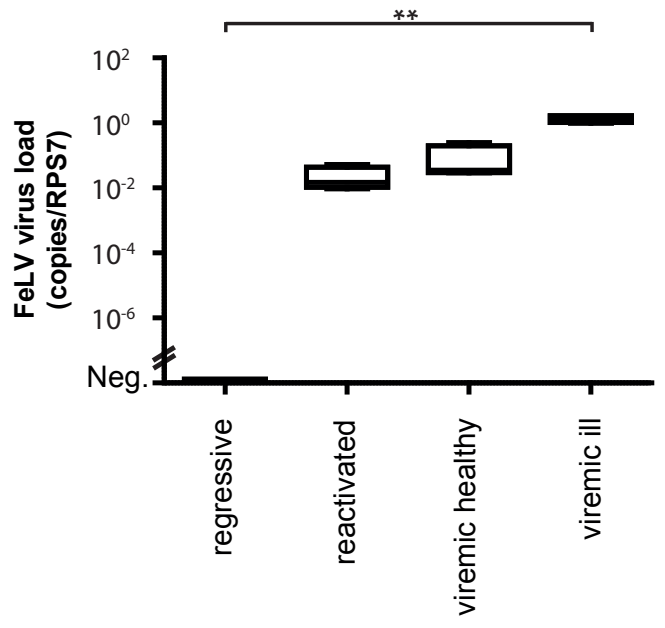

Cat group 
A

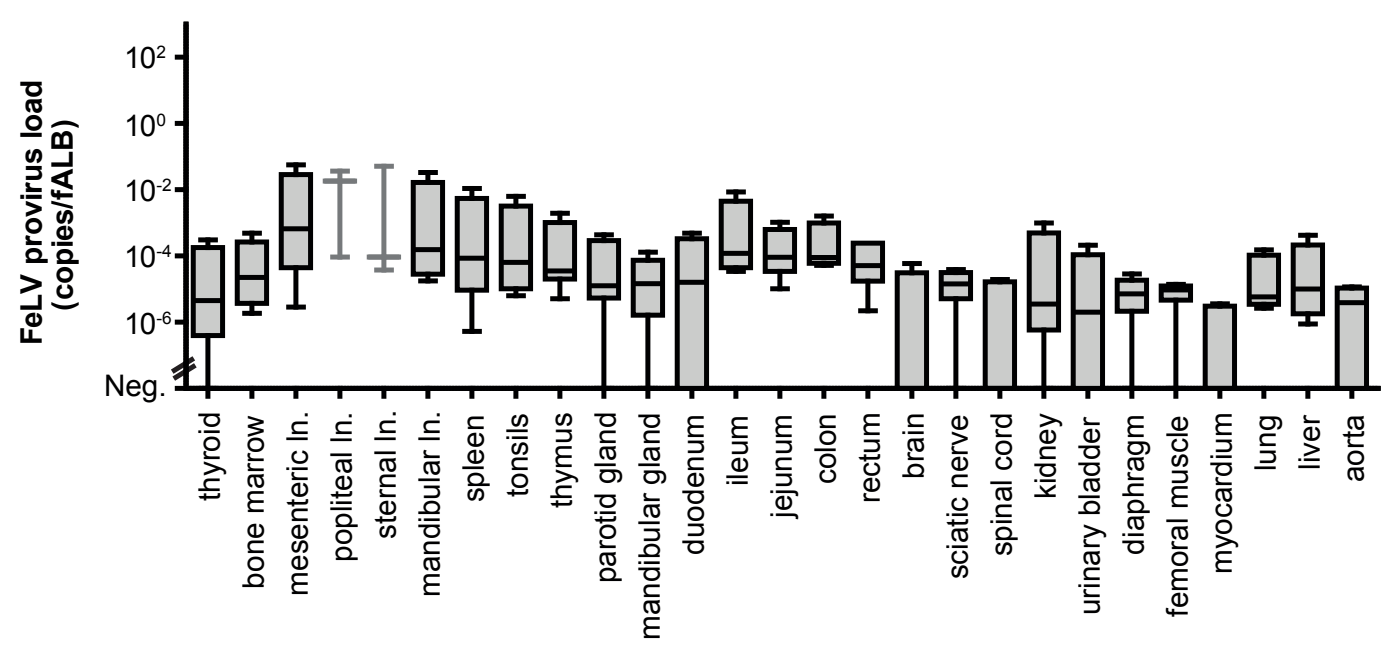

B

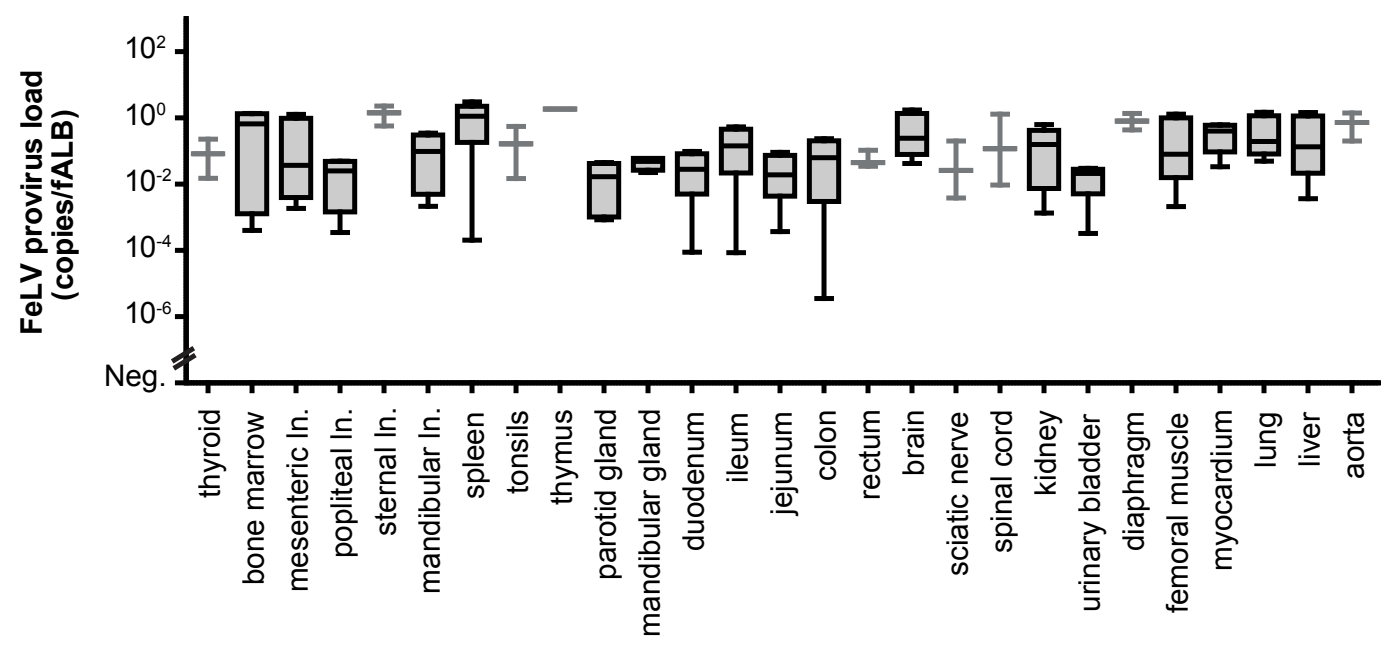

C
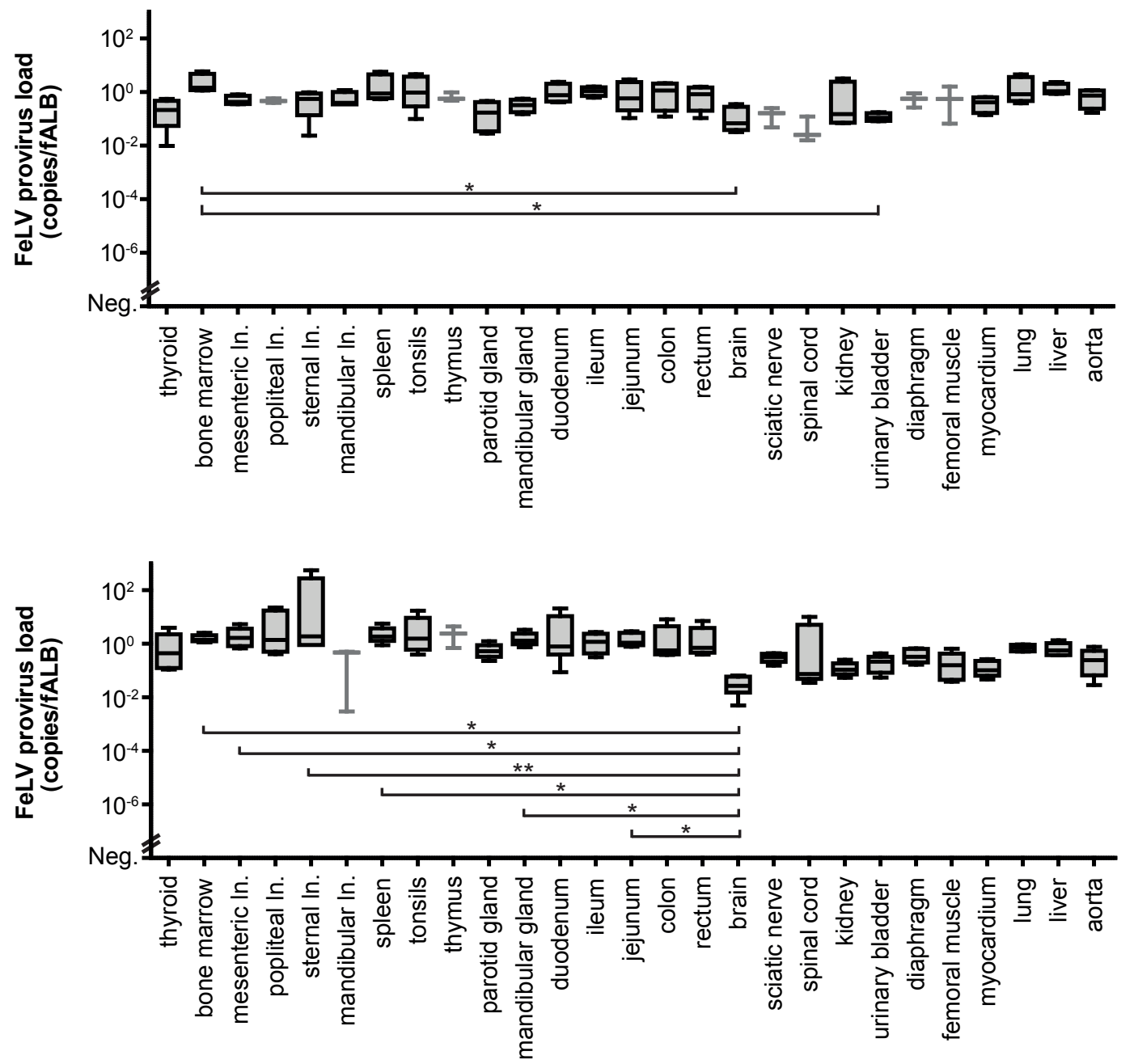
A

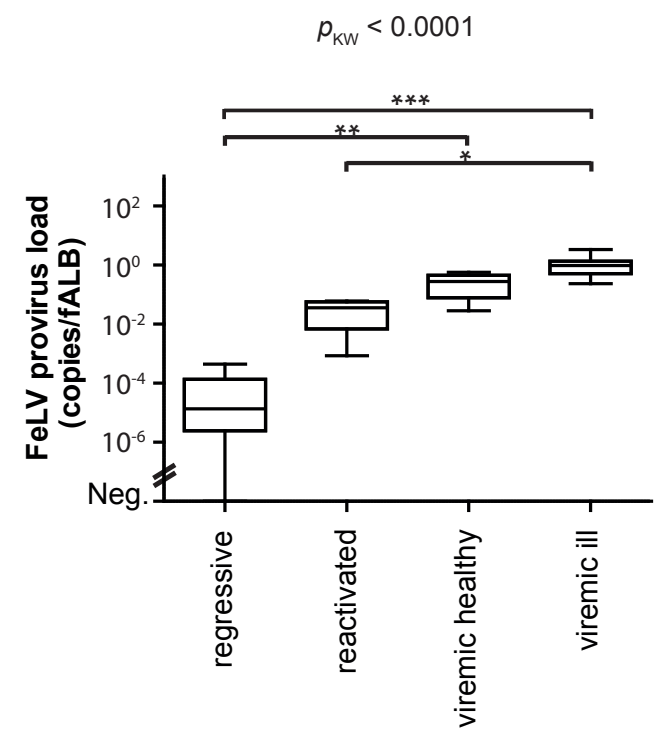

Cat group

C

$$
p_{\mathrm{kW}}=0.0012
$$

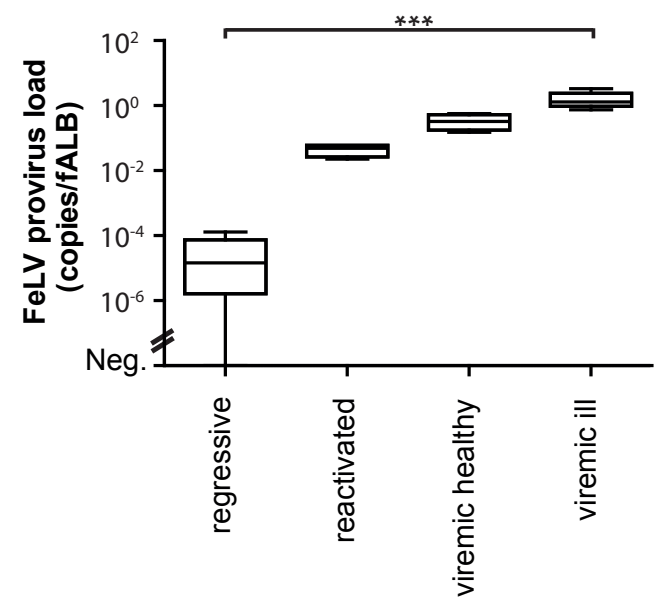

Cat group
B

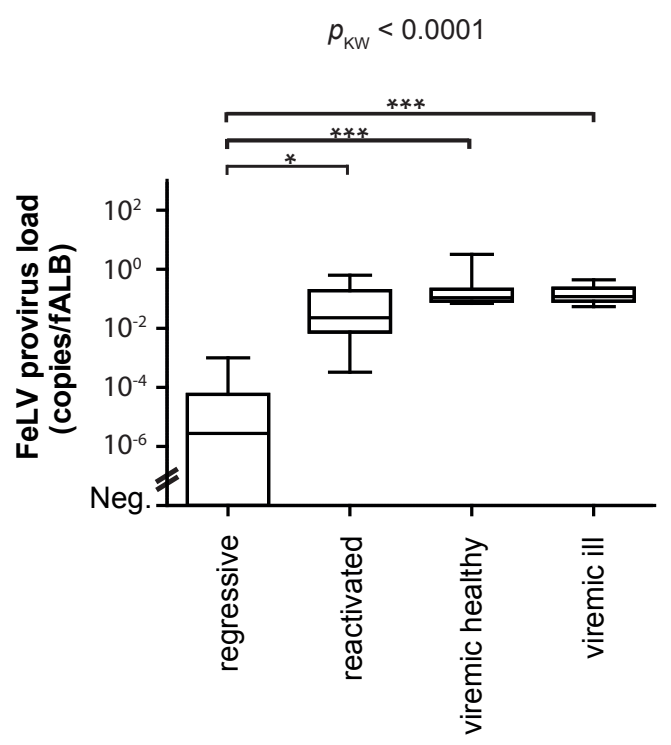

Cat group

D

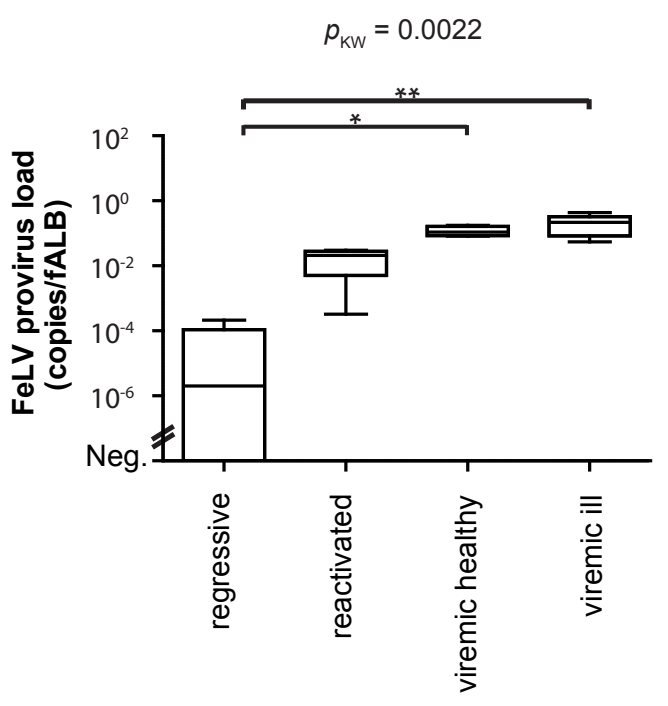

Cat group 
Suppl. Fig. 1
Click here to

Click here to download Supplementary Material: 14_11_05_Suppl. Fig.1_p27.pdf

(1)
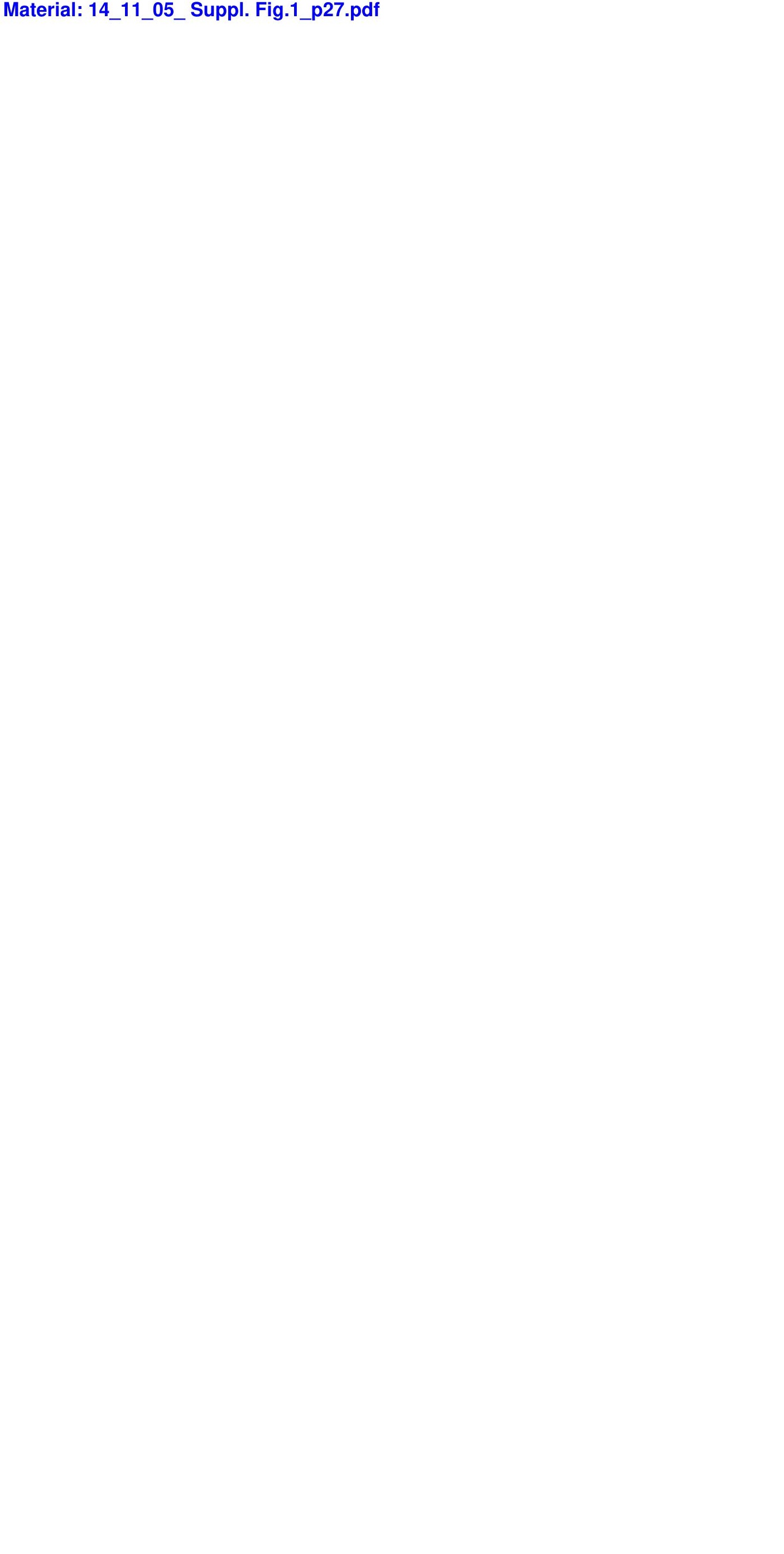
